\title{
Globalization and domestic conflict ${ }^{\dagger}$
}

\author{
Michelle R. Garfinkel \\ University of California, Irvine \\ Stergios Skaperdas \\ University of California, Irvine \\ Constantinos Syropoulos \\ Drexel University
}

First Draft: May 2004

This Draft: April 6, 2006

\begin{abstract}
We examine how globalization affects trade patterns and welfare when conflict prevails domestically. We do so in a simple model of trade, in which a natural resource like oil is contested by competing groups using real resources ("guns"). Thus, conflict is viewed as ultimately stemming from imperfect property-rights enforcement. When comparing autarky with free trade in such a setting, the gains from trade have to be weighed against the possibly higher resource costs of conflict. We find that importers of the contested resource gain unambiguously. By contrast, exporters of the contested resource lose under free trade, unless the world price of the resource is sufficiently high. Regardless of what price obtains in the world market, countries tend to over-export the contested resource relative to what we would observe if there were no conflict; for some range of prices, the presence of conflict even reverses the country's comparative advantage. For an even wider range of prices, an increase in the international price of the contested resource reduces welfare, an instance of the "natural resource curse."
\end{abstract}

JEL Classification: D30, D70, D72, D74, F2, F10.

Keywords: globalization, trade openness, property rights, enforcement, insecurity, civil wars.

\footnotetext{
${ }^{\dagger}$ Previous drafts of this paper have been presented at various seminars and conferences. We are grateful to the participants and others - especially Michael McBride, Gary Milante, Johannes Münster, Gary Richardson, Ragnar Torvik and Heinrich Ursprung — for thoughtful comments. Skaperdas' research was supported by a research and writing grant from the John D. and Catherine T. MacArthur Foundation.
} 


\section{Introduction}

In the debate regarding the effects of globalization, economists often take the rigorous neoclassical paradigm of trade as their starting point. ${ }^{1}$ Canonical versions of that paradigm assume that property rights are perfectly and costlessly enforced. Under such conditions, greater trade openness and, more generally, globalization are typically found to be beneficial. However, in many circumstances, property rights either are not well-defined or are costly to enforce. It is, therefore, only natural to ask how such deviations from the canonical paradigm of trade would influence our assessment of globalization. $^{2}$

For the most part, economic analyses of imperfectly enforced property rights have concentrated on open-access resources - fisheries, environmental resources, the commons in general - in which over-exploitation is the main source of inefficiency. With regard to the effects of globalization, Chichilnisky (1994) and Brander and Taylor (1998) have shown how removing the barriers to trade of an open-access resource can further stimulate its over-exploitation and lead to lower welfare. ${ }^{3}$

In this paper, we adopt a different approach, one that enables us to explore an altogether different set of inefficiencies arising from imperfect property-rights enforcement in relation to globalization-namely, the costs of enforcement and conflict within a country. ${ }^{4}$ Some costs of enforcement,

\footnotetext{
${ }^{1}$ See, for example, Bhagwati's (2004) multi-faceted discussion of the benefits of globalization. Stiglitz (2002) provides a different view, emphasizing the role of finance and international organizations, such as IMF and the World Bank.

${ }^{2}$ The specification and enforcement of property rights in a modern economy would seem to require (i) the presence of a state that can define these rights legislatively, (ii) an independent judiciary and non-corrupted power to enforce them, and (iii) the fiscal ability to maintain that infrastructure. Olson (2000, p.183) dubbed the modern markets that require property rights specification and enforcement, in contrast to the spontaneous markets of much of history that can rely on self-enforcement, as socially-contrived. However, even a near-complete specification of property rights cannot ensure costless enforcement. Given the resources devoted to enforcement by the state, individual parties may need to spend time or money on litigation and related activities to defend their rights.

${ }^{3}$ Hotte et. al. (2000) examine the effect of trade in an open-access resource but also allow for private enforcement and its evolution in a dynamic context.

${ }^{4}$ Skaperdas and Syropoulos $(1996,2001,2002)$ have adopted this approach to explore the welfare consequences of greater openness in the presence of conflict between nations
} 
such as those reflected in the resources regularly expended in litigation and related activities as individuals and groups try to protect their rights, are observed everywhere, even in high-income countries. Many countries, however, face more severe and costly enforcement problems that manifest themselves in a variety of forms of domestic conflict, including strikes and lockouts, military coups, low-level ethnic, religious or class rivalries, as well as rampant basic insecurity that the state is simply unable to curtail. As Rodrik (1998, 1999) has argued, managing such conflicts is critical for successful economic development. An even more important case of problematic enforcement is simply that of civil wars. The economic costs of civil conflicts have been overwhelming during the post-World War II period. The costs range from the resources allocated directly to arming and those destroyed in the struggle to the indirect losses associated with a reduction in investment and trade due to greater insecurity as well as other allocative effects that can extend well beyond the duration of the war. ${ }^{5}$

We suppose that a potentially tradeable natural resource, like oil, is contested by different domestic groups. ${ }^{6}$ The degree of openness to interna-

who possibly trade with the rest of the world. See Barbieri and Schneider (1999) for a review of the recent scholarship, produced largely though not exclusively by political scientists, on trade and conflict. This scholarship has resulted primarily in two opposing views: (i) the liberal view, that trade between nations would promote peace; and (ii) the realist view, that the effect of trade would have a negative effect or, at best, no effect.

${ }^{5}$ Recent studies of these effects, conducted by researchers at the World Bank, are distilled in Collier et. al. (2003). With the methodology developed by Lucas (1987) to estimate the welfare costs of the business cycle, Hess (2003) estimates the welfare costs of conflict coming from its effects on consumption alone for 147 countries spanning the period 1960-1992 to be on average 8 percent of steady-state consumption. The individual estimates for some countries are, not surprisingly, a bit smaller. For the United States, for example, the estimated cost is 3.2 percent. However, even this estimate is far greater than the Lucas-type estimate of the welfare cost of the business cycle in the United States [Hess, p. 17]. Moreover, the estimates for some lower-income countries are dramatically higher - e.g., the cost is 65 percent in Iraq and 40.5 percent in Angola.

${ }^{6}$ For a survey of the various contested natural resources around the globe and the problems they induce, see Klare (2001). There is now a fairly sizeable empirical literature on the relationship between a country's natural resource wealth and civil war. As discussed by Ross (2004) in his synthesis and review, the evidence is quite mixed; and while there appear to be some regularities, very little has been done to distinguish between different theoretical explanations. To get a flavor for some of the difficulties inherent in empirical work of this kind, see Sambanis (2004). While we do not add directly to the empirical literature, our framework offers new insights of relevance for the theory. 
tional markets faced by the contending parties affects not only the stakes of the contest (the value of the disputed resource), but the opportunity costs of contestation and conflict as well. To highlight the ways in which openness matters, we examine conflict in a small country under two polar regimes: autarky and free trade. One possibility is that free trade induces less arming and less domestic conflict, in which case free trade unambiguously yields higher welfare. The other possibility is that free trade induces more arming and conflict; in this case, the familiar gains from trade must be balanced against the increased costs of arming and conflict. Some of our main findings are summarized below.

First, importers of the contested resource under free trade unambiguously gain relative to the autarkic regime. In addition to realizing the regular gains from trade, such countries also experience a reduction in their costs of conflict. To be more precise, because the price of the contested resource is lower in global markets, its price under free trade is lower than it would be under autarky. As such, removing the barriers to trade with other nations reduces the conflict at home, thereby increasing welfare by more than it would were property rights perfectly and costlessly enforced.

Second, exporters of the contested resource under free trade could lose in comparison to autarky. The closer the international price of the contested resource is to its autarkic price, the more likely is such an outcome. At the autarkic price, there are no gains from trade, and the levels of conflict under the two regimes are identical. But, as the international price of the contested resource rises above its autarkic level, a shift to free trade intensifies domestic conflict so that its costs are higher than the gains from trade. Only when the international price of the contested resource rises above some threshold are the gains from trade sufficiently high to compensate for the (still increasing) costs of conflict, so that trade becomes preferable to autarky.

Third, an increase in the international price of the contested resource could reduce the exporting country's welfare. More likely when the international price is especially close to its value under autarky, this effect could be viewed as an instance of the "natural resource curse" — that is, the tendency 
for natural-resource abundant countries to have weak economic growth (see, for example, Sachs and Warner 1995 and Ross 2003). ${ }^{7}$ The reduction in welfare reflects an increase in the intensity with which groups contest the resource as its value rises in global markets over a certain price range, generating a higher cost of conflict that swamps the larger gains from trade that also come with the higher price. $^{8}$

Fourth, for a certain range of international prices, domestic conflict reverses the country's comparative advantage. To be more precise, if all property were perfectly secure or costlessly enforced such that there were no conflict between groups, the country would be a net-importer of oil over that price range; domestic conflict, however, implies that the country is instead a net-exporter. More generally, whether the international price of oil falls within that range or not, the conflict that emerges between groups as they compete for control of the natural resource distorts their production decisions, to reduce the quantity of other commodities supplied domestically relative to the aggregate domestic supply of the contested resource; in short, domestic conflict imparts a positive bias on the country's net export of the contested resource (oil) relative to the benchmark case where property is secure. Our analysis implies, then, that a country's trade pattern is not invariant to the emergence of domestic conflict. Treating the trade pattern of any of the many countries that experience civil wars and other forms of domestic conflict as indicative of their true comparative advantage either in empirical studies or for policy purposes appears unjustified.

Finally, as a country becomes richer in "oil" or when the degree of inse-

\footnotetext{
${ }^{7}$ See Robinson, Torvik, and Verdier (2003) for an overview of this literature.

${ }^{8}$ Dal Bó and Dal Bó (2004) similarly find that an increase in the international price of the natural resource can induce a greater degree of conflict; however, the source and the nature of conflict in their analysis differ from ours. The particular mechanism we study is closer to that featured in Hodler's (2004) analysis of rivaling groups, though his emphasis is more on the degree of fractionalization, whereas ours is on the degree of insecurity - which depends on institutions. Indeed, the evidence presented by Mehlum, Moene, and Torvik (2006), that the curse is associated only with countries having weak institutions, suggests that institutions matter for understanding regularly observed variation in the effects of resource booms. Robinson, Torvik, and Verdier (2003), who study an alternative mechanism which is based on electoral politics and resource extraction, also rely on differences in institutions (degrees of security) to explain the observed cross-sectional variation.
} 
curity rises, the range of international prices for which autarky is superior to free trade and the range over which the natural resource curse occurs widen; that is, both endowments and "institutions," the latter in the form of security, determine the welfare consequences of globalization.

\section{The basic setting: contesting a resource}

We present our analysis in the context of a highly simplified neoclassical model of trade, modified to allow for imperfect property rights enforcement. Despite the simplicity of the model, our findings are qualitatively robust; and, in a supplementary appendix, we show how the results can be generalized in an extended version of the Heckscher-Ohlin model of trade. ${ }^{9}$

Consider a country populated by $N$ groups, indexed by $i$. Each group $i$ is endowed with $T^{i}$ and $L^{i}$ units of secure land and labor, respectively, which can be used to produce consumption goods. For simplicity, we assume here that there is only one potential use for land, the extraction of oil, and that one unit of land yields one unit of oil. Labor, however, can be used to produce, also on a one-to-one basis, butter as well as guns. Let $G^{i}$ denote group $i$ 's level of arming or guns. ${ }^{10}$ Then, $L^{i}-G^{i}(\geq 0)$ units of labor will be available for the production of butter; therefore, group $i$ 's maximal production of butter will be $\max \left\{L^{i}-G^{i}, 0\right\}$.

Oil and butter are final consumption goods, produced under perfectly competitive conditions. They can be traded domestically or, depending on the trade regime, internationally. Let $O^{i}$ and $B^{i}$ represent group $i$ 's consumption of oil and butter respectively. The preferences of each group $i$ take the Cobb-Douglas form,

$$
U\left(O^{i}, B^{i}\right)=\left(O^{i}\right)^{\alpha}\left(B^{i}\right)^{\beta}
$$

$i=1,2, \ldots, N$, where $\alpha \in(0,1)$ and $\alpha+\beta=1$.

We suppose that groups have secure possession over the goods they pro-

\footnotetext{
${ }^{9}$ See, in particular, Appendix B.2.

${ }^{10}$ Note that "guns" can stand for any costly appropriative activity that subtracts from useful production and welfare - e.g., ordinary rent-seeking, influence activities or litigation.
} 
duce and over those they exchange, as well as the endowments we have labelled as "secure." Where our analysis departs from much of the economics literature on trade lies in the assumption that there exists some additional property within the country, $T_{0}$, which groups contest. ${ }^{11}$ All groups would like to take control of the contested territory, particularly for its oil. However, due to imperfect institutions of governance and enforcement, claims to this territory can be settled only via overt conflict or, equivalently in our model, under the threat of conflict.

It is precisely the contestability of this territory that motivates groups to allocate resources to arming. In particular, a group's production of guns enhances its chances of securing $T_{0}$ and the oil it contains. But arming is costly. To produce an additional gun, a group must forego the production of some butter. Below we explore how groups balance these effects at the margin and especially how trade openness influences the trade-off for gunsversus-butter production. As will become obvious below, the effects depend critically on the ratio of insecure land in the country, $T_{0}$, to the country's aggregate endowment of land, $\bar{T} \equiv T_{0}+\sum_{i=1}^{N} T^{i}$. Henceforth, we will refer to this ratio as the degree of insecurity, and denote it by $\tau=T_{0} / \bar{T} \in[0,1]{ }^{12}$

We model intergroup interactions, given $\tau>0$, as a winner-take-all contest, in which the probability that group $i$ emerges as the winner, $q^{i}$, depends positively on the relative amount of guns it produces. To be more precise, let the aggregate quantity of guns produced by all groups be denoted by $\bar{G} \equiv \sum_{i=1}^{N} G^{i}$, and the vector of guns that excludes $G^{i}$ by $G^{-i}$. Then, group $i$ 's probability of winning is specified as follows:

$$
q^{i} \equiv q\left(G^{i}, G^{-i}\right)= \begin{cases}G^{i} / \bar{G} & \text { if } \bar{G}>0 \\ 1 / N & \text { otherwise }\end{cases}
$$

\footnotetext{
${ }^{11}$ Insofar as exchange reflects the factor content of goods traded, it should not matter for our central results whether the commodities or the factors used to produce them are subject to dispute.

${ }^{12}$ As suggested above, the degree of insecurity, which we treat as exogenously determined, would depend on the strength of the state's institutions of governance and enforcement. But, as will become evident below, the intensity of conflict as reflected in the production of guns, is determined endogenously, depending on, among other factors, the degree of insecurity and the trade regime.
} 
for $i=1,2, \ldots, N$. According to this specification, group $i$ 's probability of winning is increasing in its own allocation to arms, $q_{G^{i}}^{i}>0$, and decreasing in the allocation to arms by all other groups, $q_{G^{j}}^{i}<0, j \neq i .{ }^{13}$

The timing of actions is as follows:

(i) Each group $i$ chooses its allocation of labor to guns production, $G^{i}$, taking the other groups decisions, $G_{j} j \neq i$, as given. Let $G$ denote the vector of all groups' gun choices. The implied production of butter for each group $i$ is $\max \left\{L^{i}-G^{i}, 0\right\}$.

(ii) Given the choices of guns $(G)$ and the technology of intergroup conflict as described in equation (2), one group emerges as the "winner" of the contest and takes control of the disputed land; if group $i$ is the winner, its land endowment and thus production of oil are $T^{i}+T_{0}$; otherwise, its land endowment and production of oil are $T^{i}$.

(iii) Then, given the production of butter and oil by all groups, competitive trade takes place.

We examine the incentives to arm and the resultant welfare of each group under two polar trade regimes: autarky and free trade. Under autarky, there is no trade with the outside world, and prices are determined domestically within an integrated market. Under free trade, assuming that the country is small, prices are given in international markets.

To derive the expected payoffs under these two regimes, we need to identify first the indirect utility functions implied by (1) and describe some of their properties. To proceed, let $\widetilde{T}^{i}$ denote group $i$ 's contingent land

\footnotetext{
${ }^{13}$ First introduced by Tullock (1980), this functional form has been used extensively in the rent-seeking literature as well as in the literatures on tournaments and conflict and falls within the general class of contest success functions, axiomatized by Skaperdas (1996): $q\left(G^{i}, G^{-i}\right)=f\left(G_{i}\right) / \sum_{j=1}^{N} f\left(G^{j}\right)$, where $f(\cdot)$ is a non-negative, increasing function. Also see Hirshleifer (1989), who investigates the properties of two important functional forms of this class, including the "ratio success function," where $f(G)=G^{m}$ with $m>0$, which simplifies to (2) when $m=1$.
} 
endowment, where as previously described,

$$
\widetilde{T}^{i}= \begin{cases}T^{i}+T_{0} & \text { if group } i \text { emerges as the winner in the contest; } \\ T^{i} & \text { otherwise. }\end{cases}
$$

for $i=1,2, \ldots, N$. Furthermore, let $p$ denote the relative price of oil measured in units of butter. The production structure specified above implies that the prices of guns and labor are also 1. We can now write group $i$ 's contingent income or revenue function as

$$
R^{i} \equiv R\left(p, \widetilde{T}^{i}, L^{i}-G^{i}\right)=p \widetilde{T}^{i}+L^{i}-G^{i}
$$

$i=1,2, \ldots, N$. Abstracting from international transfers of income, aggregate expenditure on butter and oil must be equal to this measure of income or GDP. ${ }^{14}$ Imposing this constraint at the group level, group $i$ 's contingent indirect utility function implied by (1) can be written as

$$
V^{i} \equiv V\left(p, R\left(p, \widetilde{T}^{i}, L^{i}-G^{i}\right)\right)=\mu(p)\left[p \widetilde{T}^{i}+L^{i}-G^{i}\right]
$$

$i=1,2, \ldots, N$, where $\mu(p)=\beta^{\beta}(\alpha / p)^{\alpha}$ represents each group's marginal utility of income. One can verify that group $i$ 's contingent demand and supply functions for oil are respectively $\alpha R^{i} / p$ and $\widetilde{T}^{i}$; therefore, group $i$ 's excess demand function for oil, given the realization of $\widetilde{T}^{i}$, is

$$
M^{i}=\frac{\alpha R^{i}}{p}-\widetilde{T}^{i}
$$

$i=1,2, \ldots, N$, which is positive if the group demands oil and negative if it supplies it. ${ }^{15}$

\footnotetext{
${ }^{14}$ GDP, as typically measured, includes expenditures on arming. Since such expenditures are not productive and arms are not directly consumed, their inclusion in GDP makes this aggregate a misleading measure of welfare.

${ }^{15} \mathrm{It}$ is worth noting at this point that our assumption that the utility function is homogeneous of degree one implies that each group behaves as if it is risk neutral. Specifically, for any given choice of guns, each group $i$ would be indifferent between (a) engaging in actual conflict where $q^{i}$ equals the probability it will win the entire plot of the contested land and (b) dividing the contested land in which case $q^{i}$ equals group $i$ 's share. The reader is free to use either interpretation of the model.
} 
Differentiation of group $i$ 's indirect utility function with respect to the relative price, $p$, and its guns, $G^{i}$, using (5), yields

$$
d V^{i}=\mu(p)\left[-M^{i} d p-d G^{i}\right]
$$

$i=1,2, \ldots, N$. The first term inside the brackets weighted by the marginal utility of income represents the welfare effect of an exogenous price increase. If group $i$ 's excess demand for oil $\left(M^{i}\right)$ is positive, the effect is negative; otherwise, the effect is positive. The second term inside the brackets, similarly weighted by the marginal utility of income, represents the marginal cost to group $i$ of producing an additional gun, given $\widetilde{T}^{i}$. When group $i$ produces more guns, its production of butter must fall, implying (for fixed $\widetilde{T}^{i}$ ) less income and a reduction in its overall welfare.

Given the allocation of resources to the production of guns by all groups, $(G)$, the relative price of oil that solves $\sum_{i=1}^{N} M^{i}=0$ is the market-clearing price that will prevail in the country in the absence of international trade (autarky). Denoting that price by $p_{A}$, where " $A$ " indicates the value of the variable under "autarky," one can verify that

$$
p_{A}=\frac{\alpha}{\beta} \frac{\sum_{i=1}^{N}\left(L^{i}-G^{i}\right)}{\left(T_{0}+\sum_{i=1}^{N} T^{i}\right)} .
$$

To flesh out some of the implications of this expression, let the aggregate labor endowment be denoted by $\bar{L} \equiv \sum_{i=1}^{N} L^{i}$, and recall the analogous definitions for labor $(\bar{L})$ and guns $(\bar{G})$. Then, the autarkic price, $p_{A}$, can be written as follows:

$$
p_{A}=\frac{\alpha}{\beta}\left[\frac{\bar{L}-\bar{G}}{\bar{T}}\right] \text {. }
$$

As revealed by this expression, $p_{A}$ does not depend on the distribution of either labor or land across groups; nor does it depend on the distribution of guns. Instead, it depends only on the aggregate quantities. Note especially that, when a greater share of the country's aggregate labor endowment is allocated to guns production, $\bar{L}-\bar{G}$, the amount of butter produced domestically necessarily falls; hence, as $(7)$ shows, $p_{A}$ depends negatively on the 
aggregate level of guns, $\bar{G}$. This property holds more generally, as long as guns production is more labor intensive relative to the country's labor-land endowment ratio. ${ }^{16}$

\section{The no-conflict case as a benchmark}

Before exploring the consequences of trade openness under conflict, it is helpful for later comparisons as well as for developing some intuition for our results to consider briefly the hypothetical case in which property rights are perfectly secure - that is, when there is no dispute over land $(\tau=0)$ such that groups have no incentive to arm $(\bar{G}=0)$. Equation (7) implies that, in this no-conflict or "Nirvana" case, the autarkic price, $p_{A}^{n}$, equals:

$$
p_{A}^{n}=\frac{\alpha}{\beta} \bar{L} / \bar{T}=\frac{\alpha}{\beta} l
$$

where $l \equiv \bar{L} / \bar{T}$ indicates the country's aggregate labor-land endowment ratio. In turn, summing (3) across the $N$ groups shows that, under autarky with complete security, the country's national income is $\bar{R}_{A}^{n}=p_{A}^{n} \bar{T}+\bar{L}=$ $l \bar{T} / \beta$. Then, using (4), one can verify that aggregate welfare is

$$
\bar{W}_{A}^{n}=\mu\left(p_{A}^{n}\right) \bar{R}_{A}^{n}=\mu\left(\frac{\alpha}{\beta} l\right) \frac{l}{\beta} \bar{T},
$$

where as previously defined, $\mu(p) \equiv \beta^{\beta}(\alpha / p)^{\alpha} .{ }^{17}$ The welfare of the individual groups can similarly be written as functions of their initial endowments. In the case of identical groups, the welfare of each one would be $\bar{W}_{A}^{n} / N$.

Under free trade, the relative price of oil $p$ would be given by international markets. Then, with the maintained assumption of complete security of land endowments, aggregate welfare, again calculated using (4), would be

$$
\bar{W}_{T}^{n}(p)=\mu(p)(p \bar{T}+\bar{L})=\mu(p)(p+l) \bar{T} .
$$

Supposing that groups are identical, the welfare of each would be $\bar{W}_{T}^{n}(p) / N$.

\footnotetext{
${ }^{16}$ See Appendix B.2.

${ }^{17}$ Using the solution for $p_{A}^{n}$ shown in (8) with this definition for $\mu(p)$, one can verify that aggregate welfare under autarky in this benchmark case simplifies to $\bar{W}_{A}^{n}=\bar{L}^{\beta} \bar{T}^{\alpha}$.
} 


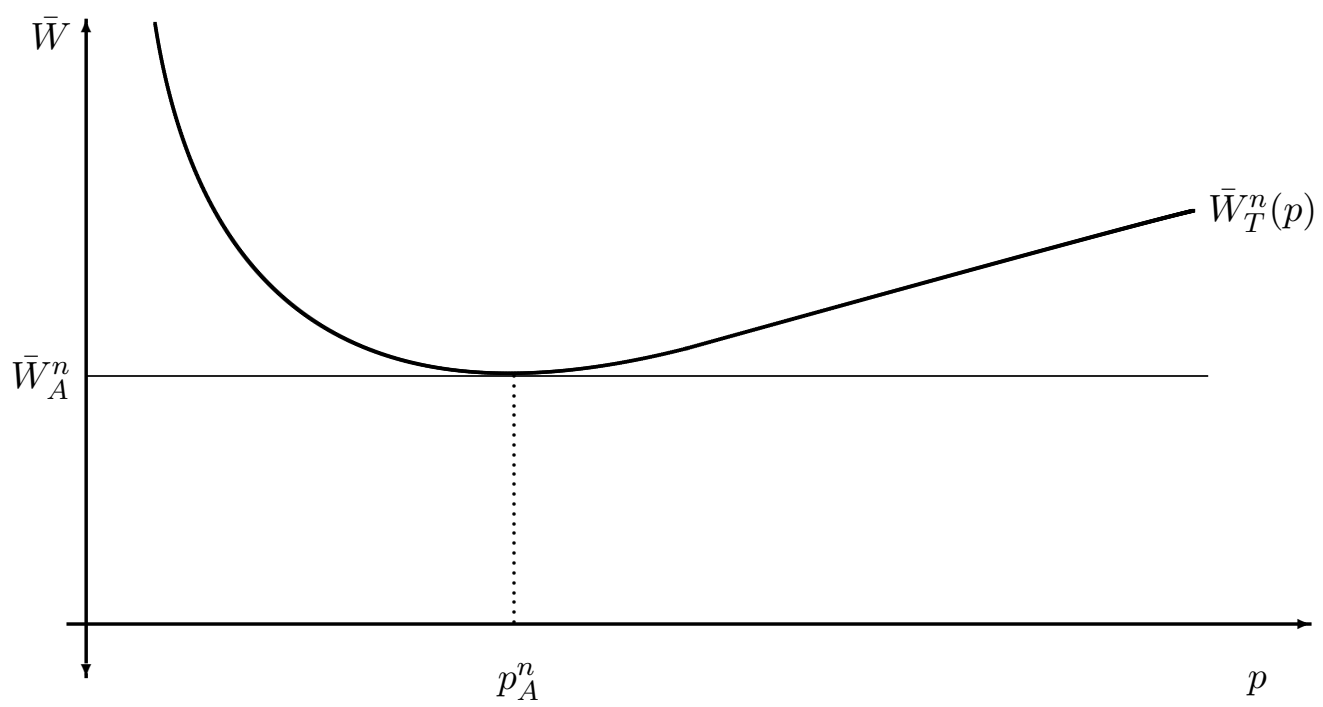

Figure 1: Free trade without conflict

As one can easily verify, $\bar{W}_{T}^{n}(p)$ is a strictly quasi-convex function of $p$, reaching its minimum at $p_{A}^{n}$, as depicted in Figure 1 . To the left of $p_{A}^{n}$ where the international price of oil is lower than the autarkic price, the country would import oil and export butter. To the right of $p_{A}^{n}$, where the international price of oil is higher than the autarkic price, the country would be an exporter of oil and an importer of butter. Clearly, in the hypothetical case where the groups' land endowments are perfectly secure, welfare would be at least as high under free trade as that under autarky.

\section{Conflict under alternative trading regimes}

We now consider the case where groups' land endowments are not fully secure, $\tau>0$, resulting in domestic conflict. First we examine the equilibrium allocation of resources under the regime of autarky and then we turn to the equilibrium allocation under the regime of free trade. 


\subsection{Autarky}

Under autarky, given the country's aggregate production of guns, $\bar{G}$, the relative price of oil is determined by (7), regardless of the outcome of the contest for control of the territory under dispute, $T_{0}$. Group $i$ 's land endowment will equal $T^{i}+T_{0}$ with probability $q\left(G^{i}, G^{-i}\right)$ and $T^{i}$ with probability $1-q\left(G^{i}, G^{-i}\right)$. Then, from equation (4), group $i$ 's expected payoff under autarky will be:

$$
W_{A}^{i}\left(G ; p_{A}\right)=\mu\left(p_{A}\right)\left[p_{A}\left(T^{i}+q^{i} T_{0}\right)+L^{i}-G^{i}\right],
$$

$i=1,2, \ldots, N$, where, as defined above, $G$ represents the vector of gun choices by all groups $i=1,2, \ldots, N$, and $q^{i}$ is specified in (2). We suppose that each group factors in the effect that its own choice of guns has on the relative price, $p_{A}$. However, groups make their choices simultaneously. Given our specifications for production, preferences, and the contest success function, a unique Nash equilibrium can be shown to exist.

At an interior optimum $G_{A}^{i *} \in\left(0, L^{i}\right)$, the following condition is satisfied for each group $i$ :

$$
\begin{aligned}
\frac{\partial W_{A}^{i}\left(G_{A}^{i *} ; p_{A}\right)}{\partial G^{i}}= & \mu\left(p_{A}\right)\left(q_{G^{i}}^{i} p_{A} T_{0}-1\right)+\left[\mu ^ { \prime } ( p _ { A } ) \left[p_{A}\left(T^{i}+q^{i} T_{0}\right)\right.\right. \\
& \left.\left.+L^{i}-G_{A}^{i *}\right]+\mu\left(p_{A}\right)\left(T^{i}+q^{i} T_{0}\right)\right] \frac{\partial p_{A}}{\partial G^{i}} \\
= & \mu\left(p_{A}\right)\left[\left(q_{G^{i}}^{i} p_{A} T_{0}-1\right)-\widehat{M}^{i} \frac{\partial p_{A}}{\partial G^{i}}\right]=0
\end{aligned}
$$

where $\widehat{M}^{i}$ denotes group $i$ 's expected excess demand for oil, which is derived analogously to (5) using Roy's identity:

$$
\widehat{M}^{i}=\frac{\alpha}{p_{A}}\left[p_{A}\left(T^{i}+q^{i} T_{0}\right)+L^{i}-G_{A}^{i *}\right]-\left(T^{i}+q^{i} T_{0}\right)
$$

$i=1,2, \ldots, N$. The first term inside the brackets in the last line of (12) weighted by the marginal utility of income represents the net expected marginal benefit of guns, keeping the autarkic price $p_{A}$ constant. As described 
earlier, the production of an additional gun enhances group $i$ 's chances of taking control of the disputed land, $T_{0}$ and the oil contained therein. As long as the relative price of oil $p_{A}$ is not too low, this expected net benefit is positive. The second term inside the brackets, again weighted by the marginal utility of income, represents the indirect effect that an additional gun would have on group $i$ 's expected payoff by influencing the relative price of oil. The sign of this indirect effect depends on whether the group is a net buyer $\widehat{M}^{i}>0$ or seller $\widehat{M}^{i}<0$ of oil.

In what follows, for ease of comparison, we suppose that groups are identical. From this assumption and the expectation of the market-clearing condition, $\sum_{i=1}^{N} \widehat{M^{i}}=0$, it follows that no group expects to be a net seller or buyer of oil: $\widehat{M}^{i}=\widehat{M}=0$, for all $i{ }^{18}$ Groups behave, in this case, as if they can have no influence on the country's autarkic price. Accordingly, group $i$ 's optimizing choice of guns satisfies the condition, $q_{G^{i}}^{i} p_{A} T_{0}-1=0 .{ }^{19}$ That quantity of guns and the implied autarkic price are respectively

$$
\begin{aligned}
G_{A}^{*} & =\frac{(N-1) T_{0} p_{A}^{*}}{N^{2}}=\frac{\alpha \tau(N-1) \bar{L}}{\beta N^{2}+\alpha \tau N(N-1)} \forall i \\
p_{A}^{*} & =\frac{\alpha N l}{\beta N+\alpha \tau(N-1)},
\end{aligned}
$$

where as previously defined $\tau \equiv T_{0} / \bar{T}>0$ indicates the degree of insecurity. As (13a) shows, the optimizing choice of guns, $G_{A}^{*}$, is strictly positive as long as there is more than one group in competition for $T_{0}(N>1)$ and depends positively on the autarkic relative price of oil, $p_{A}^{*}$. It is also necessarily less than the group's labor endowment, $\bar{L} / N$.

The solution in $(13 \mathrm{~b})$ shows that the autarkic price itself $p_{A}^{*}$, like the

\footnotetext{
${ }^{18}$ Note that our assumption of ex ante homogeneity does not preclude trade. Specifically, interpreting the conflict over $T_{0}$ as a winner-take-all contest, there will be ex post heterogeneity: the group that takes control of the land and its oil emerges as the sole net seller of oil, whereas all other groups emerge as net buyers. However, when we interpret $q^{i}$ as shares instead of probabilities, the assumption that groups are identical ex ante implies that they are identical ex post as well. As such, there would be no trade: $M^{i}=\widehat{M}^{i}=0 \forall i$.

${ }^{19}$ Even if groups were not identical, this condition would be the relevant one, provided that each group behaved as a price taker in its choice of guns.
} 
autarkic price under "Nirvana" $p_{A}^{n}=\alpha l / \beta$, is increasing in the aggregate labor endowment relative to the aggregate land endowment, $l \equiv \bar{L} / \bar{T}$. But, in contrast to $p_{A}^{n}, p_{A}^{*}$ is decreasing in the degree of insecurity, $\tau$, and in the number of groups in competition, $N$. Thus, the ratio of the two prices, given by

$$
\frac{p_{A}^{*}}{p_{A}^{n}}=\frac{\beta N}{\beta N+\alpha \tau(N-1)}
$$

is strictly less than 1 for $\tau>0$ and $N>1$, and also decreasing in the degree of insecurity, $\tau \in(0,1)$, as well as in the number of groups, $N>1$. The effects of $\tau$ and $N$ on the ratio $p_{A}^{*} / p_{A}^{n}$ can be attributed to labor being an essential input into the production of guns. Specifically, with either a larger $\tau$ or $N$, the conflict at home becomes more intense, implying a greater diversion of resources away from the production of butter and a higher relative price of butter or equivalently a lower relative price of oil. ${ }^{20}$

Under the assumption that groups are identical, aggregate welfare is:

$$
\bar{W}_{A}^{*}=\mu\left(\frac{\alpha N l}{\beta N+\alpha \tau(N-1)}\right) \frac{\bar{T} N l}{\beta N+\alpha \tau(N-1)},
$$

where $\mu(p) \equiv \beta^{\beta}(\alpha / p)^{\alpha}$ represents the marginal utility of income as defined earlier. It is straightforward to show that autarkic aggregate welfare in the absence of conflict, $\bar{W}_{A}^{n}$, is always greater than autarkic aggregate welfare under conflict, $\bar{W}_{A}^{*}{ }^{21}$ As such, under the maintained assumption that groups are identical, the welfare of any individual group would be lower under conflict as well. ${ }^{22}$

\footnotetext{
${ }^{20}$ As noted below, these effects hold for more general production structures, assuming that oil (butter) production is more land (labor) intensive, where the labor-land factor intensity ratio in the production of guns exceeds the labor-to-land endowment ratio, $l$. [See Appendix B.2 for details.]

${ }^{21}$ Using the simplified solution for $\bar{W}_{A}^{n *}$ shown in footnote 17 , it is possible to rewrite (15) as $\bar{W}_{A}^{*}=\bar{W}_{A}^{n *} \phi$ where $\phi \equiv[N \beta /(N \beta+\alpha \tau(N-1))]^{\beta}$. Since $\phi<1$ whenever $\tau>0$ given $N>1$, it follows that $\bar{W}_{A}^{*}<\bar{W}_{A}^{n *}$.

${ }^{22}$ Note that, with variation across groups, no unique set of comparisons would exist. Specifically, for any given distribution of the secure land endowment, $(1-\tau) \bar{T}$, across $i$ along with the implied gun expenditures and expected winner of the contested land, $\tau \bar{T}$, in the conflict case, there are many possible allocations of the country's entire land endowment $\bar{T}$ in the no conflict case.
} 
The following proposition summarizes our main findings thus far: ${ }^{23}$

Proposition 1 (Autarky) Suppose that competing groups are identical and that barriers preclude trade between countries, but groups within a given country may trade freely.

(i) The autarkic price under conflict $\left(p_{A}^{*}\right)$ is strictly less than the autarkic price under no conflict $\left(p_{A}^{n}\right)$ and is decreasing in the degree of insecurity $(\tau)$. Furthermore, the ratio of $p_{A}^{*}$ to $p_{A}^{n}$, as shown in equation (14), is also decreasing in the degree of insecurity $(\tau)$ and the number of groups competing for the territory under dispute $(N)$.

(ii) Autarkic aggregate welfare under no conflict, $\bar{W}_{A}^{n}$, is always higher than autarkic aggregate welfare under conflict, $\bar{W}_{A}^{*}$.

\subsection{Free trade}

Under free trade, each group can trade, without restrictions, butter and oil at a relative price $p$ which is determined in international markets. Moreover, we suppose that this price cannot be influenced by any group or by the country as a whole. In other words, the country can be considered "small". ${ }^{24}$ Using equation (4), with $\widetilde{T}^{i}=T^{i}+q^{i} T_{0}$, the expected payoff of group $i$ in this case equals

$$
W_{T}^{i}(G ; p)=\mu(p)\left[p\left(T^{i}+q^{i} T_{0}\right)+L^{i}-G^{i}\right],
$$

where as defined above $G$ represents the vector of gun choices by all groups $i=1,2, \ldots, N$. At the symmetric interior optimum we have:

$$
\frac{\partial W_{T}^{i}\left(G_{T}^{*} ; p\right)}{\partial G^{i}}=\mu(p)\left(q_{G^{i}}^{i} p T_{0}-1\right)=0,
$$

\footnotetext{
${ }^{23}$ It should be fairly obvious, given the result that autarkic price depends only on aggregate quantities and our homothetic specification for preferences that, while the presentation above is based on the assumption of identically distributed endowments, these findings extend beyond the symmetric case.

${ }^{24}$ Supposing that the groups and the country as a whole are large enough to affect international prices, and that they recognize their effects in their strategic decisions would unnecessarily complicate our derivations without qualitatively changing our results. In a similar model, but with a focus on conflict between nations instead of that within nations, Skaperdas and Syropoulos (2002) allow for a strong effect of individual players on international prices.
} 
from which we can solve for the equilibrium production of guns under trade when land endowments are not perfectly secure:

$$
G_{T}^{*}=\frac{(N-1) p T_{0}}{N^{2}}=\frac{(N-1) p \tau \bar{T}}{N^{2}}
$$

for all $i$, where $\tau \equiv T_{0} / \bar{T}$. Note that, even when the secure land endowments are not identically distributed across groups, the equilibrium would be symmetric. That is, provided the relevant resource constraint is satisfied, groups of different sizes will produce the same quantity of guns.

What relevant resource constraints do we have in mind? Since groups have, by assumption, access to international markets, it seems reasonable to suppose that they can trade the right to obtain guns beyond what can be obtained domestically (that is, beyond $L^{i}$ ), against the oil that can be obtained from the group's secure land endowment $\left(T^{i}\right)$ alone, or even against the oil that the group expects to obtain from its participation in the domestic conflict $\left(q\left(G^{i}, G^{-i}\right) T_{0}\right)$. As Collier et. al. (2003, p. 77) state: "A particularly remarkable recent development is for rebel groups to raise finance by selling the advance rights to the extraction of minerals that they currently do not control, but which they propose to control by purchasing armaments financed through the sale of extraction rights." Former President of the Democratic Republic of Congo, Lawrence Kabila, financed his rebellion against Mobutu Sese Seko with such a scheme. Similarly, Ross (2003, p. 33) cites reports of former President of Congo-Brazzaville Denis Sassou-Nguesso financing his private militias through pledges of future oil contracts, whereby he was able to come to power. Over the past decade, buying arms in international markets has become far easier than it had been in the past. Indeed, there now exist international private security firms that offer comprehensive packages, including everything from tactical advisors to whole units complete with attack helicopters and jets. Such military "imports" have been decisive factors in countries like Sierra Leone and Angola [see Davis 2000 and Singer 2003].

In accordance with such practices, we assume here that, in the free trade regime, groups can borrow against their expected land holdings $\left(T^{i}+q^{i} T_{0}\right)$ 
to procure guns in international markets at their domestic opportunity cost. Then, the optimizing guns choice for each group $i$ is $G_{T}^{*}$ as shown in (17). However, for the sake of completeness, we do consider in the appendix the alternative case where groups cannot trade in arms globally. ${ }^{25}$

Then, combining (17) with (16) shows that group $i$ 's equilibrium expected payoff under free trade, $W_{T}^{i *}(p)$, equals:

$$
W_{T}^{i *}(p)=\mu(p)\left[p\left(T^{i}+\frac{T_{0}}{N^{2}}\right)+L^{i}\right]
$$

which is strictly quasi-convex in $p$, reaching its minimum at

$$
p_{\min }^{i}=\frac{\alpha}{\beta}\left[\frac{N^{2} L^{i}}{N^{2} T^{i}+T_{0}}\right]
$$

$i=1,2, \ldots, N$. Since $G_{T}^{*}$ is the same for all $i$, each group has an equal chance of securing $T_{0}$. Thus, as (18) and (19) show, under free trade, any variation in secure endowments across groups will be fully reflected in variation in their expected payoffs for any given price. ${ }^{26}$

But, under the assumption of identical groups, aggregate welfare and the (unique) welfare-minimizing price become respectively

$$
\begin{aligned}
\bar{W}_{T}^{*}(p) & =\mu(p)\left[p\left(1-\frac{N-1}{N} \tau\right)+l\right] \bar{T} \\
& =\bar{W}_{T}^{n}(p)-\mu(p) p \frac{N-1}{N} \tau \bar{T} \\
p_{\min } & =\frac{\alpha N l}{\beta N-\beta \tau(N-1)}
\end{aligned}
$$

Then, the properties described below follow straightforwardly.

Proposition 2 (Free Trade) Suppose the competing groups are identical.

(i) The international price that minimizes the country's aggregate welfare under trade and conflict $\left(p_{\min }\right)$ is strictly greater than the autarkic

\footnotetext{
${ }^{25}$ See Appendix B.1. This case is interesting in its own right, but it also has some important policy implications that complement our findings.

${ }^{26}$ Strictly speaking, this result requires that, if there is any variation in the distribution of land endowments across groups, the degree of variation should not be too large.
} 
price under no conflict $\left(p_{A}^{n}\right)$, and is increasing in the degree of insecurity $(\tau)$ and the number of groups competing for the insecure property $(N)$. Furthermore, the ratios

$$
\frac{p_{\min }}{p_{A}^{n}}=\frac{\beta N}{\beta N-\beta \tau(N-1)} \quad \text { and } \quad \frac{p_{\min }}{p_{A}^{*}}=\frac{\beta N+\alpha \tau(N-1)}{\beta N-\beta \tau(N-1)}
$$

are both increasing in the degree of insecurity, $\tau$.

(ii) For any given international price $p$, aggregate welfare under conflict, $\bar{W}_{T}^{*}(p)$, is strictly lower than aggregate welfare under no conflict, $\bar{W}_{T}^{n}(p)$. Furthermore, the higher is the degree of insecurity $(\tau)$, the lower is $\bar{W}_{T}^{*}(p)$.

Part (ii) of Proposition 2 is to be expected, as insecurity induces arming that reduces welfare. The interpretation and significance of part (i) will become evident in the next section in our comparison of the two trading regimes.

\section{Comparing the two trading regimes under conflict}

Having characterized the allocation of resources under the two polar trading regimes, we are now ready to compare them in terms of both arming and welfare. The comparison reveals two key forces at play here: (i) the well known gains from trade that favor trade over autarky, as was demonstrated above in the benchmark case without conflict; and (ii) the induced effects of trade openness on the groups' incentive to fight over the contested resource, which may or may not favor trade over autarky.

Consider first the level of arming. Note that, whereas guns under autarky depend only on the endowments and other parameters of the model as shown in (13a), guns under free trade critically depend on the relative price $p$ and positively so as shown in (17). Using (13a) and (17), we calculate the ratio of guns in the two regimes, $\theta$, which provides a convenient summary measure:

$$
\theta \equiv \frac{G_{T}^{*}}{G_{A}^{*}}=\frac{p}{p_{A}^{*}}
$$


As this expression shows, gun choices under free trade are larger than that under autarky if and only if the international relative price of guns is higher than the autarkic price.

The logic here is straightforward: A high price of oil induces more production of guns because land and oil are more valuable in international markets and thus induce more competition for the capture of the contested land. When $\theta>1$ the groups and the country as a whole export oil. By contrast, when $\theta<1$, oil is less valuable internationally than it is domestically and the country imports oil and produces fewer guns than under autarky.

Moving on to the relative appeal of free trade, note that the payoffs under autarky equal the payoffs under free trade if the international price equals the autarkic price: $\bar{W}_{T}^{*}\left(p_{A}^{*}\right)=\bar{W}_{A}^{*}$. Since $\bar{W}_{T}^{*}(p)$ is strictly quasi-convex in $p$ and obtains its minimum at $p_{\text {min }}$, how welfare under free trade, $\bar{W}_{T}^{*}(p)$, ranks relative to welfare under autarky, $\bar{W}_{A}^{*}$, depends on how $p_{\min }$ is related to the autarkic price $p_{A}^{*}$. In particular, if these two prices were to coincide, then the expected payoffs under autarky would fall below the expected payoffs under trade everywhere except at that minimum price. However, from Proposition 2 part (i) we have $p_{\min }>p_{A}^{n}$ and from Proposition 1 part (i) we have $p_{A}^{n}>p_{A}^{*}$. Therefore, we must have $p_{\min }>p_{A}^{*}$, implying that there exists some range of international prices for which the groups are better off under autarky than under trade.

But we can be more precise in characterizing this range of prices. In particular, given the strict quasi-convexity of $\bar{W}_{T}^{*}(p)$, there exists another price $p^{\prime}>p_{\min }$ defined uniquely by the condition, $\bar{W}_{T}^{*}\left(p^{\prime}\right)=\bar{W}_{A}^{*}$, such that for all $\widetilde{p} \in\left(p_{A}^{*}, p^{\prime}\right)$, the expected payoffs under free trade are lower than the payoffs expected under autarky $\left(\bar{W}_{T}^{*}(\widetilde{p})<\bar{W}_{A}^{*}\right)$, whereas for prices outside that interval the payoffs expected under trade are at least as high as those expected under under autarky $\left(\bar{W}_{T}^{*}(\widetilde{p}) \geq \bar{W}_{A}^{*}\right)$. This range of prices is illustrated in Figure 2.

We summarize the key implications of our analysis as they relate to the welfare comparison of the two regimes in the following proposition:

Proposition 3 (Relative Appeal of Free Trade) Suppose the competing 


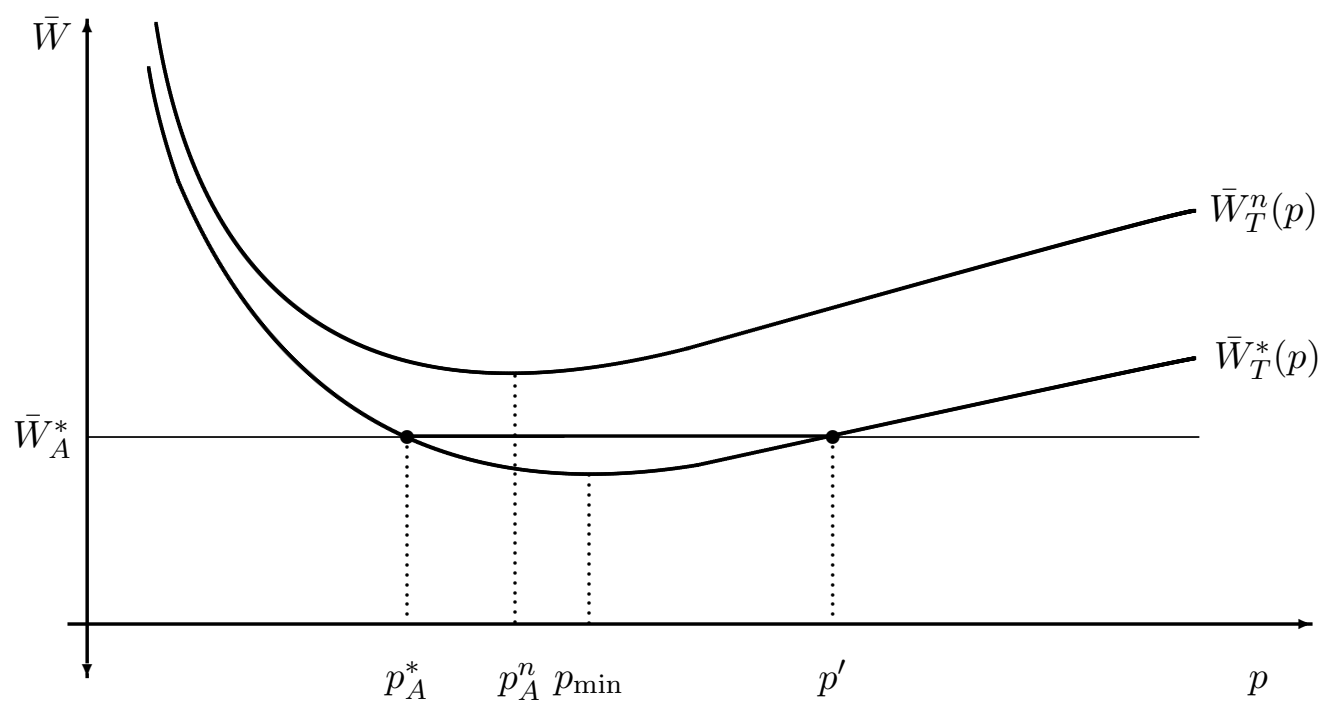

Figure 2: Free trade with conflict

groups are identical.

(i) When the international price of oil $p$ is lower than $p_{A}^{*}$ or higher than $p^{\prime}$, welfare under free trade is higher than welfare under autarky.

(ii) When the international price of oil is between $p_{A}^{*}$ and $p^{\prime}$, welfare under autarky is higher than welfare under free trade.

(iii) The price $p^{\prime}$ is increasing in the degree of insecurity $\tau$. The ratio $p^{\prime} / p_{A}^{*}$ is increasing in the degree of insecurity $\tau$ as well. Thus, the range of prices for which autarky dominates trade is increasing in the degree of insecurity.

When the international price for oil $p$ is lower than its autarkic price $\left(p_{A}^{*}\right)$, the production of guns under trade is lower. In this case, removing the barriers to trade reduces the groups' incentives to fight over the contested resource, implying that domestic conflict is less intense. With this benefit and the familiar gains from trade, there should be no doubt that welfare is higher than it would be under autarky. However, as the international price of oil rises, domestic conflict intensifies, becoming just as severe as it 
is under autarky once the international price reaches the price that obtains under autarky $\left(p=p_{A}^{*}\right)$ while, at the same time, the gains from trade fall to zero. It is at this point, as shown in Figure 2, that welfare under autarky coincides with welfare under free trade.

As the international price continues to rise above the autarkic level, domestic conflict intensifies further. But while the gains from trade rise above zero, these gains are not sufficiently large to compensate for the higher burden of guns; thus, as the international price of oil rises above the autarkic price, welfare under free trade falls below its autarkic level. Yet, as Proposition 3 indicates, further increases in the international price of oil eventually make free trade relatively more appealing. That is to say, when the international price of oil becomes sufficiently high $\left(p>p^{\prime}\right)$, the gains from winning the valuable land and selling the oil in the global marketplace become very large and outweigh the welfare cost of guns.

Part (iii) of the Proposition, the proof of which is given in the appendix (A), establishes that the range of international prices for which autarky is superior to trade $\left(p \in\left(p^{*}, p^{\prime}\right)\right)$ expands as insecurity $(\tau)$ increases, an intuitively plausible but non-trivial property. Figure 3 illustrates this property and also shows how an increase in the degree of insecurity shifts the welfare curve under free trade down.

As noted above, both $p_{A}^{*}$ and $p_{A}^{n}$ are increasing in the labor-land endowment ratio $l \equiv \bar{L} / \bar{T}$. One can verify from (20c) that $p_{\min }$ is also increasing in $l$. Thus, an increase in the labor-land endowment ratio would be reflected in a rightward shift in the welfare curves drawn in Figure $2 .{ }^{27}$ A larger $l$ implies a wider range of international prices for which free trade is superior (i.e., $p<p_{A}^{*}$ ), since the country is an importer of oil and an exporter of butter over that range.

Throughout this analysis, we have assumed that, in the free trade regime, groups are able to procure arms in global markets, borrowing against their expected land holdings, $\bar{T} / N$, such that the labor resource constraint, $\bar{L} / N-$ $G_{T}^{*}>0$, never binds. Without questioning the relevance of this assumption,

\footnotetext{
${ }^{27}$ It is not possible to sign $d p^{\prime} / d l$ generally; however, it is possible to verify, for sufficiently large $l$, that $p^{\prime}$ is also increasing in $l$.
} 


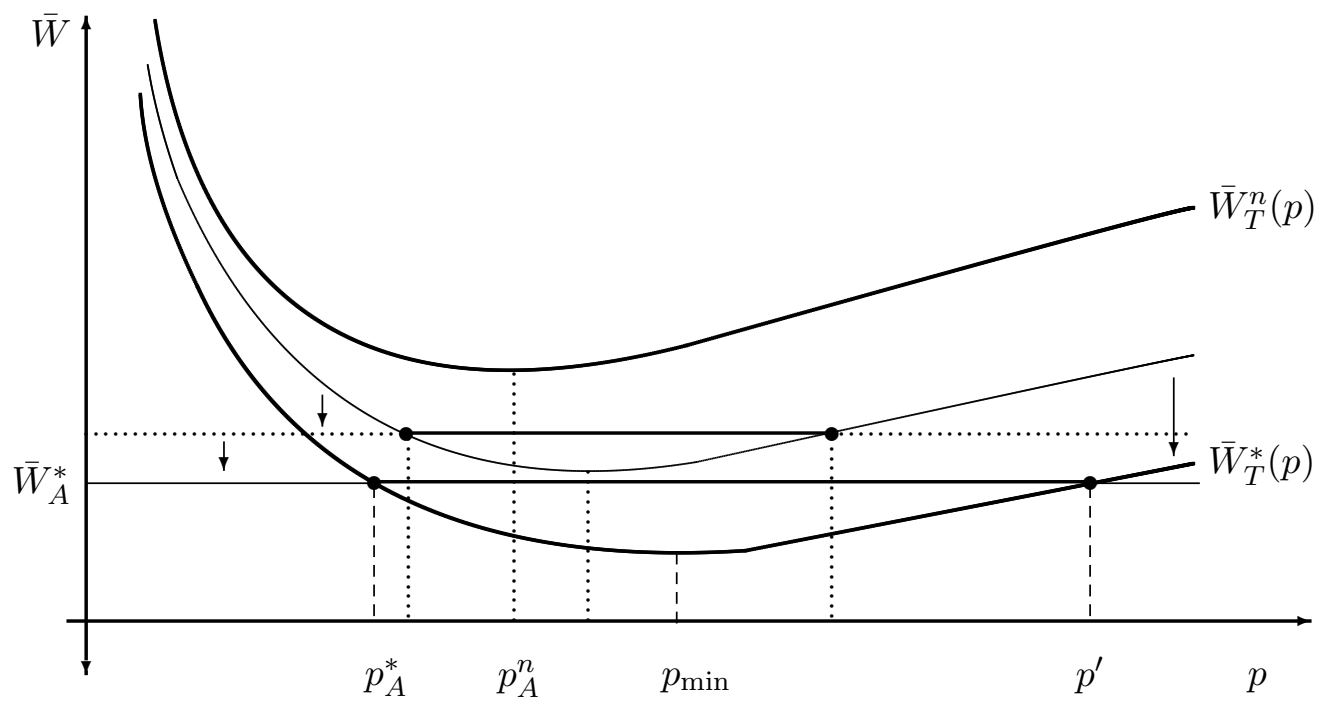

Figure 3: When the degree of insecurity rises

it seems worthwhile to note when global trade in arms is prohibited and conflict is sufficiently severe (as determined jointly by $\tau$ and $N$ ) such that groups exhaust their labor endowment in guns production alone, the range of prices for which autarky dominates free trade becomes a subset of the range as characterized here. Furthermore, the width of that range is decreasing in the degree of insecurity. These findings suggest, what upon some reflection should not be too surprising, that prohibiting trade in arms with countries where domestic conflict prevails can enhance the appeal of globalization. ${ }^{28}$

\section{$6 \quad$ Further implications}

Our analysis above shows clearly that the presence of insecure property, which paves the way for domestic conflict, can have important implications for the relative appeal of free trade. In this section, we present two additional implications of our framework. These similarly regard the effects of insecure property on trade and welfare; however, they also underscore the importance of careful measurement and interpretation of the data. The first follows

\footnotetext{
${ }^{28}$ See Appendix B.1 for details and additional results.
} 
immediately from our previous discussion in connection with Proposition 3 and is illustrated in Figure 2. It concerns the welfare effect of an increase in the international price of the contested resource.

Proposition 4 (Resource Curse) Suppose the competing groups are identical. Then, for international prices between $p_{A}^{*}$ and $p_{\text {min }}$, aggregate welfare under free trade, $\bar{W}_{T}^{*}(p)$, is decreasing in the international price $p$.

This finding is similar in spirit to what others (including, but not limited to, Sachs and Warner 1995 and Ross 2003) have called the "resource curse," but is based on a different logic. In particular, as suggested earlier, for $p \in\left[p_{A}^{*}, p_{\min }\right)$, increases in the international price of the contested resource induce a greater degree of domestic conflict. While the familiar gains from trade increase with increases in $p$ over this range, these increases are swamped by even larger increases in the burden of guns. Part (i) of Proposition 2 implies further that the range of prices for which welfare is decreasing in the international price, $\left(p_{A}^{*}, p_{\min }\right)$, depends positively on the degree of insecurity $\tau .^{29}$

It is important to note, in connection with the resource curse, that national income under free trade, given by

$$
\bar{R}_{T}^{*}(p)=\left[p\left(1-\frac{N-1}{N} \tau\right)+l\right] \bar{T},
$$

is everywhere increasing in the international price $p$, even over that range for which welfare is falling. Thus, particularly for $p \in\left[p_{A}^{*}, p_{\min }\right)$, our measure of income tends to overstate welfare. But, there is no reason to believe that commonly used measures of aggregate income (e.g., GDP) do any better. If anything, there is reason to believe that they do worse. Specifically, our theoretical construct, in contrast to conventionally used measures based on national income and product accounts, excludes expenditures on arming.

\footnotetext{
${ }^{29}$ However, as shown in the appendix, prohibiting trade in arms could truncate the range of prices for which welfare is decreasing in the international price. See Appendix B.1 for further details. In that appendix, we also consider in more detail the qualitative relation between the width of the price range for which the resource curse is relevant and the degree of insecurity.
} 
Thus, the conventional measures of national income would tend to overstate welfare by even more than our theoretical measure. But the point here is not to "advocate" our theoretical measure. Instead, the point is to note that reports of income founded on conventional income accounting might not be able to identify fully the extent of the natural resource curse. Accordingly, the curse itself might be not only more severe but also more pervasive, affecting more countries than currently believed. ${ }^{30}$

Another implication of the analysis that we point out here is that conflict also affects the pattern of trade. Specifically, when $p \in\left(p_{A}^{*}, p_{A}^{n}\right)$, the presence of insecure land endowments reverses the direction of the country's comparative advantage relative to the hypothetical scenario where land endowments are perfectly secure. To illustrate this effect, we combine (5) with (3) and (7), to calculate the country's aggregate excess demand for oil under free trade in the hypothetical case of no conflict $\left(\bar{M}_{T}^{n}(p)\right)$ and in the more realistic case of conflict $\left(\bar{M}_{T}^{*}(p)\right)$ :

$$
\begin{aligned}
\bar{M}_{T}^{n}(p) & =\beta \bar{T}\left[\frac{p_{A}^{n}}{p}-1\right] \\
\bar{M}_{T}^{*}(p) & =\beta \bar{T}\left[\frac{p_{A}^{*}}{p}-1\right] .
\end{aligned}
$$

By definition, each measure is positive when the country imports oil and negative when it exports oil. More importantly, as (21a) reveals, in the absence of conflict, the country would import oil whenever $p<p_{A}^{n}$. But (21b) shows that if, at the same time, $p>p_{A}^{*}$, then under trade with conflict, the country would export oil. This sharp divergence in the pattern of trade stems from the effect of insecure property $(\tau>0)$ to divert resources (specifically labor in this model) away from butter production to guns production. Part (i) of Proposition 1 implies that the range of prices under which such a

\footnotetext{
${ }^{30}$ Candidates for this designation would be countries that have, for example, low ranks in term of the UNDP's Human Development Index (HDI) compared to their rank in terms of GDP. Such countries appear to fall into one of either two categories: those that are significant oil exporters (like Saudi Arabia or Angola) and those that have significant domestic cleavages (like Algeria and South Africa). See the table for HDI at the following web site: http://hdr.undp.org/reports/global/2003/indicator/index.html.
} 
divergence in the pattern of trade in oil emerges, $\left(p_{A}^{*}, p_{A}^{n}\right)$, is increasing in the degree of insecurity, $\tau .{ }^{31}$

However, the influence of insecurity on a country's pattern of trade is not limited to cases where the price of oil falls within that particular range. Equation (21b) shows that a country's excess demand for oil is increasing in $p_{A}^{*}$, which Proposition 1 part (i) indicates is decreasing in the degree of insecurity. Thus, the degree of insecurity, $\tau$, generally reduces the country's excess demand for oil, thereby imparting a positive bias on the country's exports of the contestable resource for all $p$. We summarize these findings in the following proposition:

Proposition 5 (Trade Pattern Effects) The domestic demand for oil is decreasing in the degree of insecurity $\tau$, and the country over-exports oil (relative to the hypothetical no-conflict case). When the international price of oil is between $p_{A}^{*}$ and $p_{A}^{n}$, there is a reversal in the country's comparative advantage (relative to the no conflict case), with the country exporting instead of importing oil.

In oil-exporting countries where there is domestic conflict over that same resource, we would expect these exports to be higher than those that would obtain in the absence of conflict. If, for example, the resources expended on Nigeria's civil wars and the various other forms of domestic conflict that have been present there over the years were instead used in production, the local economy would have absorbed more of the oil production and less of it would have been exported.

To be sure, this trade-pattern effect extends to more general production functions for guns, as well as for butter and oil. Within a modified structure of the Heckscher-Ohlin trade model, what matters is how factor intensities compare across industries and relative to the country's labor-land

\footnotetext{
${ }^{31}$ Note that, under the assumption that groups can trade in guns as well as in oil and butter in world markets, insecurity's effect to push the country to export oil does not necessarily mean that insecurity simultaneously pushes the country to import butter. An oil-exporting country could (i) export butter, while necessarily importing guns, or (ii) import butter, while either importing or exporting guns.
} 
endowment ratio, $l \equiv \bar{L} / \bar{T}{ }^{32}$

\section{Concluding remarks}

Since 1945, at least 127 civil wars (each causing, by definition, at least 1,000 deaths) have emerged in 73 countries. The total number of casualties resulting directly from these wars is conservatively estimated to be at least 16.2 million. ${ }^{33}$ The accompanying direct and indirect economic costs have also been immense. These wars have not abated since the end of the Cold War; they have spread into Eastern Europe and Central Asia (Collier et. al, 2003, Ch.4), and many pre-existing wars last longer than they had in the past [Fearon and Laitin, 2003]. Furthermore, low-level insurgencies, civil unrest, and more conventional forms of domestic conflict are present in an additionally large number of countries, and these have their own added costs (Rodrik, 1999).

Our findings suggest that, without conflict-minimizing governance, globalization's effects can significantly deviate from those predicted by traditional trade models where all endowments are considered perfectly secure. Although for importers of oil and other natural resources opening up the economy brings the regular benefits of trade and reductions in conflict, for exporters of the same resources opening the economy to trade can very well induce increased conflict costs that more than offset the familiar gains from trade. Welfare can even fall when the price of the exported resource rises, and the country in conflict might be exporting a good that it would be importing in the absence of conflict.

The increase in domestic conflict observed in the post-war period is also correlated with the emergence of weak new post-colonial and postcommunist states that have been unable to develop the legal infrastructure, enforcement, and institutions which would be expected to manage the var-

\footnotetext{
${ }^{32}$ For details, please see the supplementary appendix, Appendix B.2.

${ }^{33}$ See Fearon and Laitin (2003, p.75) who base their findings on the Correlates of War project, among other sources. Using Singer and Singer (1994) updated to include the Kargil and Eritrean wars, they report further that the same period witnessed a much smaller number of interstate wars, with proportionately fewer casualties. This trend represents a reversal from the first 45 years of the twentieth century.
} 
ious conflicts. As even the strong states of high-income countries are said to be weakening in many of the same dimensions (see, e.g., Van Creveld, 1999), one may reasonably question whether any significant progress can be made to improve the governance of security in low-income countries without qualitative changes in the way the international economy is governed.

\section{References}

Barbieri, Katherine and Schneider, Gerald, "Globalization and Peace: Assessing New Directions in the Study of Trade and Conflict," Journal of Peace Research, July 1999, 36(4): 387-404.

Bhagwati, Jagdish, In Defense of Globalization, 2004, New York: Oxford University Press.

Brander, James and Taylor, M. Scott, "Open Access Renewable Resources: Trade and Trade Policy in a Two-Country Model," Journal of International Economics, April 1998, 44(2): 181-209.

Chichilnisky, Graciela, "North-South Trade and the Global Environment," American Economic Review, September 1994, 84(4): 851-874.

Collier, Paul, Elliott V.L., Hegre Havard, Hoeffler, Anke, ReynalQuerol, Marta, and Sambanis, Nicholas, Breaking the Conflict Trap; Civil War and Development Policy, (World Bank Policy Report), 2003, Washington, DC: World Bank and Oxford University Press.

Dal Bó, Ernesto and Dal Bó, Pedro, "Workers, Warriors and Criminals: Social Conflict in General Equilibrium," December 2004, Manuscript, University of California-Berkeley.

Davis, James R., Fortune's Warriors: Private Armies and the New World Order, 2000, Toronto: Douglas \& McIntyre.

Dixit, Avinash K. and Norman, Victor, Theory of International Trade, 1980, Cambridge: Cambridge University Press. 
Fearon, James D. and Laitin, David D., "Ethnicity, Insurgency, and Civil War," American Political Science Review, February 2003, 97(1): 75-90.

Hess, Gregory D., "The Economic Welfare Cost of Conflict: An Empirical Assessment," CESifo Working Paper, No. 852, February 2003.

Hirshleifer, Jack, "Conflict and Rent-seeking Success Functions: Ratio vs. Difference Models Of Relative Success." Public Choice, November 1989, 63(2), 101-12.

Hodler, Roland, "The Curse of Natural Resources in Fractional Countries" March 2004, University of Bern, Working Paper.

Hotte, Louis, Long, Ngo Van and Tian, Huilian, "International Trade with Endogenous Enforcement of Property Rights," Journal of Development Economics, 2000, 62: 25-54.

Lucas, Robert E., Models of Business Cycles, Oxford, 1987, UK: Basil Blackwell.

Klare, Michael T., Resource Wars: The New Landscape of Global Conflict, 2001, New York: Henry Holt and Company.

Mehlum, Halvor, Moene, Karl and Torvik, Ragnar, "Institutions and the Resource Curse," Economic Journal, January 2006, 116: 1-20.

Olson, Mancur, Power and Prosperity, 2000, New York: Basic Books.

Robinson, James, Torvik, Ragnar and Verdier, Thierry, "Political Foundations of the Resource Curse," DELTA Working Paper 2003-33, October 16, 2003.

Rodrik, Dani, "Where Did All the Growth Go? External Shocks, Social Conflict, and Growth Collapses," January 1998, NBER Working Paper 6350. 
Rodrik, Dani, The New Global Economy and Developing Countries: Making Openness Work, 1999, Baltimore: Johns Hopkins University Press.

Ross, Michael L., "The Natural Resource Curse: How Wealth Can Make You Poor," in Ian Bannon and Paul Collier (eds.), Natural Resources and Violent Conflict: Options and Actions, 2003, Washington, DC: The World Bank, 17-42.

Ross, Michael L., "What Do We Know About Natural Resources and Civil War?" Journal of Peace Research, May 2004, 41(3): 337-356.

Sachs, Jeffrey D. and Warner, Andrew, "Natural Resource Abundance and Economic Growth," Harvard Institute for International Development, 1995, Development Discussion Paper No. 517.

Sambanis, Nicholas, "Using Case Studies to Expand Economic Models of Civil War," Perspectives on Politics, June 2004, 2(2), 259-279.

Singer, J. David and Small, Melvin H., "Correlates of War Project: International and Civil War Data, 1816-1992," April 1994, ICPSR 9905.

Singer, Peter W., Corporate Warriors: The Rise of the Privatized Military Industry, 2003, Ithaca, NY: Cornell University Press.

Skaperdas, Stergios, "Contest Success Functions," Economic Theory, February 1996, 7(2), 283-90.

Skaperdas, Stergios and Syropoulos, Constantinos, "Competitive Trade With Conflict," in Garfinkel, M.R. and Skaperdas, S. (eds), The Political Economy of Conflict and Appropriation, 1996, New York: Cambridge University Press.

Skaperdas, Stergios and Syropoulos, Constantinos, "Guns, Butter, and Openness: On The Relationship Between Security And Trade." American Economic Review, Papers and Proceedings, May 2001, 91(2): 353-357. 
Skaperdas, Stergios and Syropoulos, Constantinos, "Insecure Property and the Efficiency of Exchange," Economic Journal, January 2002, 112: 133-146.

Stiglitz, Joseph, Globalization and its Discontents, 2002, New York: W. W. Norton \& Company.

Tullock, Gordon, "Efficient Rent Seeking." In Toward a Theory of the Rent Seeking Society, edited by James M. Buchanan, Robert D. Tollison, and Gordon Tullock, 1980, College Station: Texas A\&M University Press, 3-15.

Van Creveld, Martin, The Rise and Decline of the State, 1999, New York: Cambridge University Press.

\section{A Appendix: Proof of Proposition 3, part (iii).}

As noted earlier, $p^{\prime}$ is defined by $W_{T}^{*}\left(p^{\prime}\right)=W_{A}^{*}$, which, using (15) for $W_{A}^{*}$ and (20a) for $W_{T}^{*}\left(p^{\prime}\right)$, can be written as

$$
\left[\frac{\beta N l}{\beta N+\alpha \tau(N-1)}\right]^{\beta}-\frac{\alpha}{p^{\prime \alpha}}\left[p^{\prime}\left(1-\tau \frac{N-1}{N}\right)+l\right]=0 .
$$

An application of the implicit function theorem to (A.1) yields:

$$
\begin{aligned}
& \frac{\partial p^{\prime}}{\partial \tau}=-\frac{p^{\prime \alpha} A}{B}, \quad \text { where } A \equiv p^{\prime \beta \frac{N-1}{N}}-\beta p_{A}^{* \beta} \frac{N-1}{\beta N+\alpha \tau(N-1)} \\
& B \equiv \frac{\alpha l}{p^{\prime}}-\beta\left[1-\tau \frac{N-1}{N}\right] \text {. }
\end{aligned}
$$

Since $p^{\prime}>p_{A}^{*}$, we must have from the definition of $A$,

$$
A>p_{A}^{* \beta}\left[\frac{N-1}{N}-\beta \frac{N-1}{\beta N+\alpha \tau(N-1)}\right]=p_{A}^{* \beta} \frac{N-1}{N}\left[\frac{\alpha \tau(N-1)}{\beta N+\alpha \tau(N-1)}\right] .
$$

The expression on the right hand side of the equality above is strictly positive, implying $A>0$. To $\operatorname{sign} B$, note that (20c) implies $p_{\min }=\alpha l / \beta[1-$ 
$\left.\tau \frac{N-1}{N}\right]$. From the inequality $p^{\prime}>p_{\min }$, it follows that $p^{\prime} \beta\left[1-\tau \frac{N-1}{N}\right]>\alpha$, and therefore $B<0$. With (A.2), the inequalities $A>0$ and $B<0$, in turn, imply that the price $p^{\prime}$ is increasing in the degree of security $\tau: \partial p^{\prime} / \partial \tau>0$. Then, with Proposition 1 part (i), that $p_{A}^{*}$ is decreasing in $\tau$, one can verify that the ratio, $p^{\prime} / p_{A}^{*}$, is increasing in $\tau$. $\|$

\section{B Supplementary appendices}

\section{B.1 Restricted (free) trade}

In this appendix we consider the implications of a restricted trade regime. That is to say, we suppose that groups cannot procure arms in global markets when $L^{i}<G_{T}^{*}$, even when they can trade in both butter and oil. Under the maintained assumption that endowments are identically distributed, imposing this restriction implies that the resource constraint in arms production will bind for all groups if the international price for oil exceeds some threshold level. Manipulation of equation (17) shows that this threshold level, $p^{c}$, is

$$
p^{c} \equiv \frac{N l}{(N-1) \tau}
$$

In turn, with (13b), it is possible to verify that $p_{A}^{*}<p^{c}<\infty$, provided there is some degree of insecurity, $\tau>0$, given $N>1$. $^{34}$

Now, when $p \leq p^{c}$, the representative group's optimizing choice of guns, denoted here by $G_{R T}^{u *}$, is identical to the solution shown in (17); otherwise it is given by the group's labor endowment, $G_{R T}^{c *}=\bar{L} / N$. Accordingly, from (16), aggregate welfare under restricted free trade is given by the following:

$$
\bar{W}_{R T}^{*}(p)= \begin{cases}\bar{W}_{R T}^{u *}(p)=\mu(p) \bar{T}\left[p\left(1-\frac{N-1}{N} \tau\right)+l\right] & \text { if } p \leq p^{c} \\ \bar{W}_{R T}^{c *}(p)=\mu(p) \bar{T} p & \text { if } p>p^{c}\end{cases}
$$

where, as previously defined, $\mu(p) \equiv \beta^{\beta}(\alpha / p)^{\alpha}$. Obviously, $\bar{W}_{R T}^{u *}(p)$, which represents aggregate welfare when the resource constraint is not binding, is identical to that when "free trade" means "unrestricted trade", $\bar{W}_{T}^{*}(p)$,

\footnotetext{
${ }^{34}$ Since the resource constraint for arms production is not relevant under autarky, $p_{A}^{*}$ is identical to that which was derived in the main text.
} 
as shown in (20a) - all goods (oil, butter and guns) can be freely traded in the world market, all groups can use their future oil earnings from the land they appropriate as collateral for their current gun purchases, and the international price of guns equals the domestic (and constant) marginal cost. $\bar{W}_{R T}^{c *}(p)$ represents aggregate welfare when only oil and butter are traded globally and the international price is sufficiently high to render trade not only restricted, but also resource constrained. All labor is expended in the production of guns, and no butter is produced domestically in the restricted trade regime.

Using (B.1), (B.2) and (20a), one can show that, for all $p>p^{c}$, the following holds: $\bar{W}_{R T}^{c *}(p)>\bar{W}_{T}^{*}(p)$. This inequality underscores the potential value of prohibiting global trade in arms - namely, as a commitment mechanism when the state's institutions of governance and enforcement are sufficiently weak. In particular, by limiting trade to only oil and butter, it is possible to impose at least some discipline on the contesting groups, and thereby limit the wasteful absorption of resources into guns. Indeed, ruling out trade in arms between nations could enhance the relative appeal of trade between countries in other goods where property is insecure and hence domestic conflict prevails.

To proceed, observe that, since $\bar{W}_{R T}^{u *}(p)=\bar{W}_{T}^{*}(p)$, the properties of $\bar{W}_{R T}^{u *}(p)$ are identical to those we derived in the main text for $\bar{W}_{T}^{*}(p)$ : $\bar{W}_{R T}^{u *}\left(p_{A}^{*}\right)=\bar{W}_{A}^{*}$; and, provided $\tau>0, \bar{W}_{R T}^{u *}(p)$ is strictly quasi-convex in $p$, reaching a minimum at $p_{\min }>p_{A}^{*}$, where $p_{\min }$ is shown in equation (20c). Furthermore, it is easy to verify, using (B.2), that $d \bar{W}_{R T}^{c *}(p) / d p>0$. Then it follows that there exists some range of international prices of oil, $\left(p_{A}^{*}, \widetilde{p}\right)$, for which groups are better off under autarky than under restricted free trade. More importantly, this range could differ from that when groups are permitted to trade in arms as well as in butter and oil, $\left(p_{A}^{*}, p^{\prime}\right)$, as was characterized in Proposition 3. The key in identifying these differences lies analyzing the determination of $\tilde{p}$, to which we now turn.

First recall that $p^{\prime}$ is defined as the maximal solution to $\bar{W}_{T}^{*}(p)=\bar{W}_{A}^{*}$, 
which implies that $d p^{\prime} / d \tau>0 .{ }^{35}$ Now define $p^{\prime \prime}$ analogously as the (unique) solution to $\bar{W}_{R T}^{c *}(p)=\bar{W}_{A}^{*}$, which from (15) and (B.2) is given by,

$$
p^{\prime \prime} \equiv \frac{\alpha^{\frac{-\alpha}{1-\alpha}} N l}{\beta N+\alpha \tau(N-1)} .
$$

This solution shows that $d p^{\prime \prime} / d \tau<0$.

One can then show that $\widetilde{p}=\min \left\{p^{\prime}, p^{\prime \prime}\right\}$, where by the properties of $\bar{W}_{R T}^{u *}(p)$ and $\bar{W}_{R T}^{c *}(p)$ and the definition of $p^{c}$, we have the following:

$$
p^{\prime \prime} \lesseqgtr p^{\prime} \Longleftrightarrow p^{c} \lesseqgtr p^{\prime \prime}
$$

This set of related inequalities, in turn, implies that there exists a critical degree of security, which equates $p^{c}$ shown in (B.1) and $p^{\prime \prime}$ shown in (B.3), as follows

$$
\widetilde{\tau} \equiv \widetilde{\tau}(\alpha, N)=\left(\frac{\alpha^{\frac{\alpha}{1-\alpha}}-\alpha^{\frac{1}{1-\alpha}}}{1-\alpha^{\frac{1}{1-\alpha}}}\right) \frac{N}{N-1},
$$

given $\alpha \in(0,1)$ and $N$ that ensure $\widetilde{\tau} \in(0,1]$, such that

$$
\widetilde{p}=\left\{\begin{array}{lll}
p^{\prime} & \text { if } \quad \tau \leq \widetilde{\tau} \\
p^{\prime \prime} & \text { if } \quad \tau>\widetilde{\tau}
\end{array}\right.
$$

Now, if $\tau \leq \widetilde{\tau}$, the degree of insecurity and, given the number of competing groups, the resulting intensity of conflict is not sufficiently severe to make the labor resource constraint in guns production bind. In this case, the range of oil prices in global markets under which autarky dominates restricted free trade (consumption goods alone) corresponds to the range of prices under which autarky dominates unrestricted free trade (consumption goods and arms): $\left(p_{A}^{*}, p^{\prime}\right)$. By Proposition 3 (iii), this range is increasing in the degree of insecurity, $\tau{ }^{36}$

\footnotetext{
${ }^{35}$ Also see Appendix A.

${ }^{36}$ One related possibility is that, depending on preferences $(\alpha)$ and the number of groups $(N), \widetilde{\tau}>1$. In this case, since $\tau \leq 1$ by construction, $\tau<\widetilde{\tau}$, regardless of the degree of security, and hence, from (B.6), $\tilde{p}=p^{\prime}$. In fact, for any fixed value of $N>1$, there exists an $\alpha, \alpha_{o}(N) \in(0,1)$ such that $\widetilde{\tau}>1$ for all $\alpha \in\left(0, \alpha_{o}(N)\right)$. This reasoning suggests, in turn, that there exists a set of $(\alpha, N)$ pairs such that $\tilde{p}=p^{\prime}$ for any degree of insecurity,
} 
However, if $\tau>\widetilde{\tau}$, which is more likely, given the degree of insecurity, the larger is the number of groups in competition for control over the natural resource $(N)$, the range of international prices under which autarky dominates restricted free trade, $\left(p_{A}^{*}, p^{\prime \prime}\right)$, is a subset of the range under which autarky dominates unrestricted free trade, $\left(p_{A}^{*}, p^{\prime}\right)$. In this case, conflict is sufficiently severe to push groups to employ their entire labor endowments in the production of guns; yet, the restriction on trade in arms precludes any additional diversion of resources, thereby neutralizing at least some of the conflict-enhancing effect of free trade (as identified in the main text). Furthermore, one can easily verify that the width of the price range $\left(p_{A}^{*}, p^{\prime \prime}\right)$ is decreasing in degree of insecurity $\tau$. Given that the intensity of conflict is sufficiently severe (as determined jointly by $\tau$ and $N$ ), there exists a range of international prices, under which prohibiting trade in arms enhances the relative appeal of global trade, even if restricted.

These results suggest that prohibiting global trade in guns can also have important implications for the range of international prices under which the aggregate welfare is decreasing in the international price (akin to the "natural resource curse"). Recall that for the case of unrestricted free trade, that range is $\left(p_{A}^{*}, p_{\min }\right)$, with $p_{\min } \equiv \arg \min \bar{W}_{R T}^{u *}(p)$, which is shown in (20c). From our results to this point, it follows that $\bar{W}_{R T}^{*}(p)$ is strictly quasi-convex in $p$, with a kink at $p=p^{c}$ and a unique minimizer, denoted by $p_{R \cdot \min } \equiv \arg \min \bar{W}_{R T}^{*}(p)$. Since $\bar{W}_{R T}^{c *}(p)$ is increasing in $p$, the value of $p_{R \text {-min }}$ depends on whether the resource constraint is binding at an international price for oil which falls above or below $p_{\min }$. More precisely, $p_{R \cdot \min }=\min \left\{p^{c}, p_{\min }\right\}$.

Now define $\widehat{\tau} \equiv \widehat{\tau}(\alpha, N)$ as the critical value of $\tau$ that equates $p^{c}$ and $p_{\min }$. From (B.1) and (20c), this critical value is given by

$$
\widehat{\tau} \equiv \widehat{\tau}(\alpha, N)=\frac{(1-\alpha) N}{N-1}
$$

for $\alpha \in(0,1)$ and $N$ that ensure both $\widehat{\tau} \in(0,1]$. As the right hand side of this expression clearly shows, $\widehat{\tau}$ is linear in $\alpha$ and decreasing in both $\alpha$ and $\tau \in[0,1]$. 
$N$. From (B.5) and (B.7), we can see that $\widehat{\tau}(\alpha, N)>\widetilde{\tau}(\alpha, N)$ for parameter values that ensure $\widehat{\tau} \leq 1$ and $\widetilde{\tau} \leq 1$. It is now easy to verify that

$$
p_{R \cdot \min }=\left\{\begin{array}{lll}
p_{\min } & \text { if } & \tau \leq \widehat{\tau} \\
p^{c} & \text { if } & \tau>\widehat{\tau}
\end{array}\right.
$$

Since $p_{A}^{*}<p^{c}<\infty$ for all $\tau>0$ given $N>1$, whenever $p \in\left(p_{A}^{*}, p_{R \cdot \min }\right)$, welfare under restrictive free trade, $\bar{W}_{R T}^{*}(p)$ is decreasing in the international price. If $\tau \leq \widehat{\tau}$, then this price range corresponds to the analogous one derived in the case of unrestricted free trade, $\left(p_{A}^{*}, p_{\min }\right)$. Furthermore, the width of this range of prices is increasing in the degree of insecurity. However, if $\tau>\widehat{\tau}$, the price range under which the natural resource curse occurs, $\left(p_{A}^{*}, p^{c}\right)$, is a subset of the analogous price range in the case of unrestricted free trade. Moreover, the width of the price range is decreasing in the degree of security, $\tau$, given $N$.

Figure B.1 combines some of the central results of this appendix to show how the influence of prohibiting trade in arms depends qualitatively on the degree of insecurity. Specifically, the figure distinguishes between three possibilities, regarding insecurity $(\tau):{ }^{37}$

(i) Case 1: $\tau=\tau_{x} \in(0, \widetilde{\tau}$. When the degree of insecurity is relatively mild, prohibiting trade in arms influence neither the range of prices for which autarky dominates free trade, $\left(p_{A}^{*}, \tilde{p}\right)$ nor the range of prices under which aggregate welfare is decreasing in the international price under the trade regime, $\left(p_{A}^{*}, p_{R \cdot \min }\right): \tilde{p}=p^{\prime}$ and $p_{R \cdot \min }=p_{\min }$. Still, for a sufficiently high price, the labor constraint will bind.

(ii) Case 2: $\tau=\tau_{y} \in(\widetilde{\tau}, \widehat{\tau}]$. When the degree of insecurity rises slightly, prohibiting trade in arms will affect the range of prices under which autarky dominates free trade, $\left(p_{A}^{*}, \tilde{p}\right)$, but not the range of prices under which aggregate welfare is decreasing in the international price under the trade regime, $\left(p_{A}^{*}, p_{R \cdot \min }\right): \tilde{p}=p^{\prime \prime}<p^{\prime}$, but $p_{R \cdot \min }=p_{\min }$.

\footnotetext{
${ }^{37}$ The figure assumes that $\widehat{\tau} \leq 1$. As drawn in the figure, an increase in $\tau$ causes a downward shift in both $\bar{W}_{R T}^{u *}(p)$ and $\bar{W}_{A}^{*}$ as described in the main text, but as suggested above $\bar{W}_{R T}^{c *}(p)$ does not depend on $\tau$.
} 
(iii) Case 3: $\tau_{z} \in(\widehat{\tau}, 1]$ : When the degree of insecurity is relatively severe, prohibiting trade in arms affects both the range of prices under which autarky dominates free trade, $\left(p_{A}^{*}, \tilde{p}\right)$ and the range of prices under which aggregate welfare is decreasing in the international price under the trade regime, $\left(p_{A}^{*}, p_{R \cdot \min }\right): \tilde{p}=p^{\prime \prime}<p^{\prime}$ and $p_{R \cdot \min }=p^{c}<p_{\min }$.

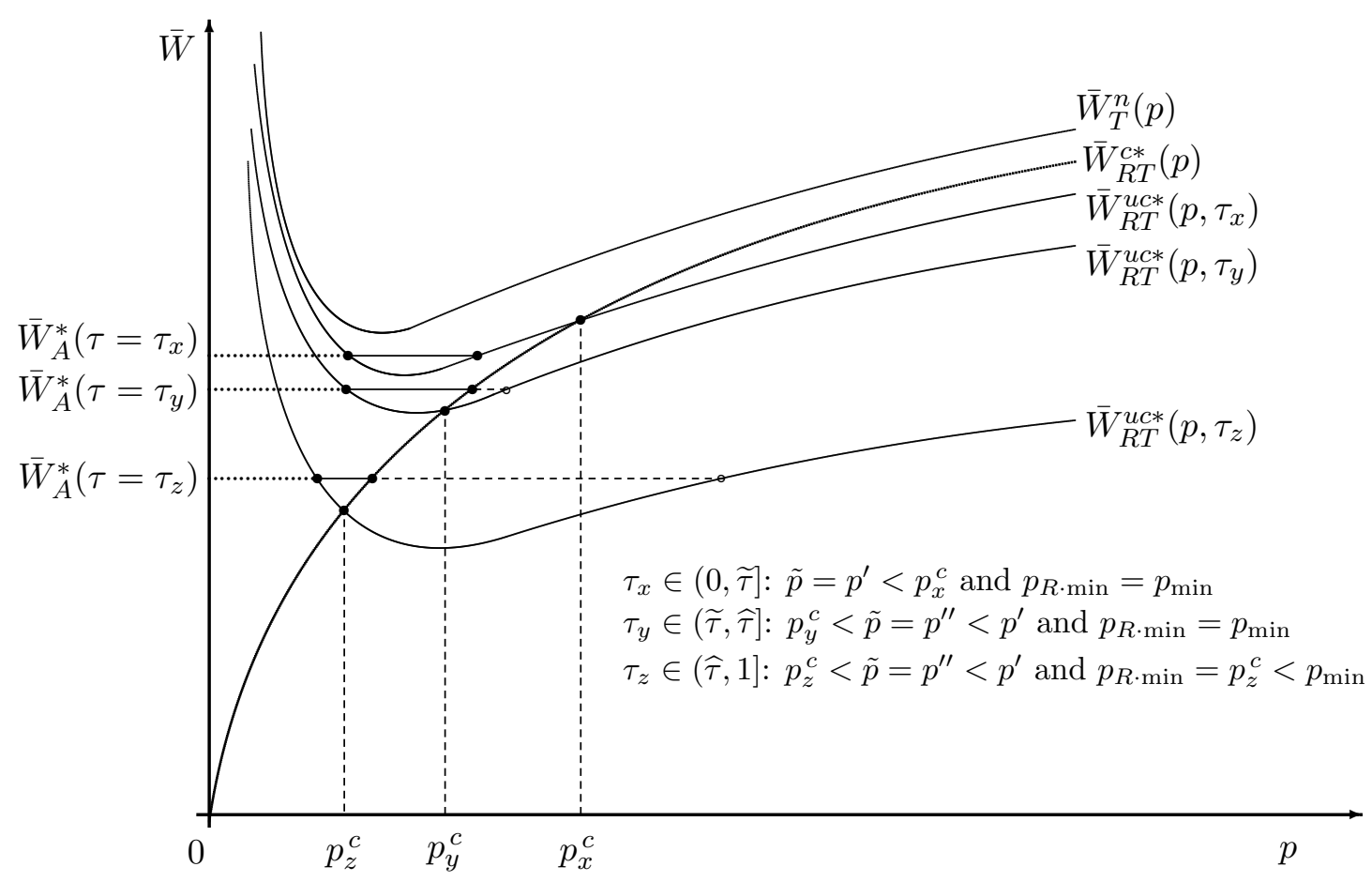

Figure B.1: When trade in arms is prohibited

The figure also illustrates how a discrete increase in the degree of insecurity, where the initial degree of insecurity is sufficiently high to make the labor constraint binding, truncates the range of prices for which autarky dominates free trade. Furthermore, the figure clearly shows that, even where the degree of insecurity is mild, prohibiting trade in arms can have beneficial effects, further enhancing the overall gains from globalization. As predicted by the theory of the second-best, given the already-existing distortions induced by insecurity, introducing another (by restricting trade) can enhance 
aggregate welfare.

\section{B.2 General production structures and the patterns of trade}

Here we outline an extension of our model in which the production structure is generalized along the lines of the standard Heckscher-Ohlin model of trade, to show how our results regarding the pattern of trade extend with some qualifications. For simplicity we focus on the case where only oil and butter can be trade internationally. As before, denote the relative price of oil (measured in units of butter) by $p$. Now let the price of labor and the price of land be denoted respectively by $w$ and $r$, and assume that all commodities can be produced using land and labor with constant returns to scale technologies. For specificity, identify the corresponding technologies for the production of these goods, $J=O, B, G$, with the unit cost functions $c^{J} \equiv c^{J}(w, r)$, which we assume are linear homogeneous and concave in their arguments. By Shephard's lemma, $c_{w}^{J}$ and $c_{r}^{J}$ indicate respectively the (conditional) unit labor and unit land requirements in the production of good $J$, where the subscript denotes the partial derivative of the cost function with respect to that factor price. The linear homogeneity of $c^{J}$ implies that the unit labor and land requirements are homogenous of degree zero and further that the labor-land factor intensity ratio in industry $J, l_{J} \equiv c_{w}^{J} / c_{r}^{J}$, is decreasing in the wage-rental ratio, $\omega \equiv w / r$.

Within this more general production structure, supposing that labor (land) is employed intensively in the production of butter (oil) - that is, $l_{B}(\omega)>l_{O}(\omega)$ for all relevant $\omega$-we identify the conditions under which (i) the autarkic relative price of oil in the presence of conflict continues to be below that which obtains in the "Nirvana" case; and, (ii) there is a tendency to over-export oil in the presence of conflict relative to the Nirvana case. ${ }^{38}$ The key condition for both results, given $l_{B}(\omega)>l_{O}(\omega)$, is that the country's (and, under symmetry, the representative group's) labor-land factor endowment ratio $l \equiv \bar{L} / \bar{T}$ is higher than the labor-land factor intensity

\footnotetext{
${ }^{38}$ While consistent with the production structure specified in the main text, this assumption on factor intensities is not as restrictive and, moreover, is not important for the central result of the paper that trade openness can aggravate domestic conflict.
} 
ratio in the production of guns: $l_{G}=c_{w}^{G} / c_{r}^{G}$. Otherwise, the results are reversed. Either way, we can see that the country's pattern of trade will depend on the presence of conflict.

\section{B.2.1 The effect of conflict on the autarkic price}

Focusing on diversified production for oil and butter, with the price of butter normalized to one, competitive pricing requires

$$
\begin{aligned}
& c^{O}(w, r)=p \\
& c^{B}(w, r)=1 .
\end{aligned}
$$

Under our assumptions, these two conditions together define the equilibrium values of $w$ and $r$ as functions of product prices. An application of the implicit function theorem to (B.9) confirms, consistent with the StolperSamuelson theorem, that an exogenous increase in the relative price of oil $(p)$ generates a disproportionate increase in the reward to the factor employed intensively in this industry (land), while reducing the real reward paid to the other factor (labor): $p r_{p} / r>1$ and $w_{p}<0$, where the subscript denotes the partial derivative with respect to that variable.

Let $\bar{X}_{J} \equiv \sum_{i=1}^{N} X_{J}^{i}$ denote the country's aggregate output of $J=O, B$, and recall that $\bar{G} \equiv \sum_{i=1}^{N} G^{i}$ indicates the country's aggregate allocation to guns. ${ }^{39}$ Then, given the quantities of labor and land resources allocated produce $\bar{G}$, factor-market clearing requires the residual quantities of labor and land, $\bar{L}-c_{w}^{G} \bar{G}$ and $\bar{T}-c_{r}^{G} \bar{G}$, be allocated to the production of consumption goods, $\bar{X}_{J}, J=B, O$, as follows:

$$
\begin{aligned}
c_{w}^{O} \bar{X}_{O}+c_{w}^{B} \bar{X}_{B} & =\bar{L}-c_{w}^{G} \bar{G} \\
c_{r}^{O} \bar{X}_{O}+c_{r}^{B} \bar{X}_{B} & =\bar{T}-c_{r}^{G} \bar{G}
\end{aligned}
$$

We will later refer to the ratio $\bar{l}_{X} \equiv\left(\bar{L}-c_{w}^{G} \bar{G}\right) /\left(\bar{T}-c_{r}^{G} \bar{G}\right)$ as the laborland residual factor endowment ratio.

\footnotetext{
${ }^{39}$ As defined in the main text, $X_{O}^{i}$ and $X_{B}^{i}$ denote group $i$ 's output levels of oil and butter, respectively, contingent on the realization, $\widetilde{T}^{i}$.
} 
With the country's factor endowments, $\bar{L}$ and $\bar{T}$, the two conditions shown in (B.10) pin down the aggregate quantities of oil and butter that will be supplied by the country, $\bar{X}_{O}$ and $\bar{X}_{B}$, as functions of $\bar{G}$ and $p$. For our purposes, it suffices to solve these equations for the relative supply of oil function (measured in units of butter):

$$
\rho(\bar{G}, p) \equiv \frac{p \bar{X}_{O}}{\bar{X}_{B}}=\frac{p c_{r}^{B}}{c_{r}^{O}} \frac{\left(l_{B}-\bar{l}_{X}\right)}{\left(\bar{l}_{X}-l_{O}\right)} .
$$

Conflict's effect on the autarkic price operates partly through $\bar{G}$ 's effect influence on this relative supply of oil. To evaluate this effect, first observe that an increase in aggregate guns, $\bar{G}$, given $p$, reduces the residual quantities of both labor and land available for the production of consumption goods. Nevertheless, we can pin down net effect of the increase in $\bar{G}$ on $\bar{l}_{X}$, as it depends on the difference between the labor-land factor endowment ratio, $l=\bar{L} / \bar{T}$, and the labor-land factor intensity ratio on the production of guns, $l_{G}=c_{w}^{G} / c_{r}^{G}$ :

$$
\frac{\partial \bar{l}_{X}}{\partial \bar{G}}=\frac{c_{r}^{G}\left(l-l_{G}\right) \bar{T}}{\left(\bar{T}-c_{r}^{G} \bar{G}\right)^{2}} \gtreqless 0 \text { if } l \gtreqless l_{G} .
$$

Whether positive or negative, the change in $\bar{l}_{X}$ then directly affects the relative supply of oil:

$$
\frac{\partial \rho(\bar{G}, p)}{\partial \bar{l}_{X}}=-\frac{p c_{r}^{B}}{c_{r}^{O}} \frac{\left(l_{B}-l_{O}\right)}{\left(\bar{l}_{X}-l_{O}\right)^{2}}<0,
$$

where the inequality, consistent with the Rybczynski theorem, follows from the assumption that labor is employed intensively in the production of butter, $l_{B}>l_{O} .{ }^{40}$ Combining these two effects, for given $p$, implies

$$
\frac{\partial \rho(\bar{G}, p)}{\partial \bar{G}}=\frac{\partial \rho(\bar{G}, p)}{\partial \bar{l}_{X}} \frac{\partial \bar{l}_{X}}{\partial \bar{G}} \lesseqgtr 0 \text { if } l \gtreqless l_{G} .
$$

\footnotetext{
${ }^{40}$ One can show more generally, with an application of the implicit function theorem to (B.10), that an increase in the quantity of land (labor) used to produce oil and butter leads to a disproportionate increase in the output of the industry that uses the factor intensively, oil (butter), and a decrease in the output by the other industry, butter (oil).
} 
If the labor-land factor endowment ratio is less than the labor-land factor intensity of guns production, $l<l_{G}$, an exogenous increase in $\bar{G}$ decreases disproportionately the residual amount of labor available for the production of oil and butter; the resulting decline in $\bar{l}_{X}$ implies an increase in the relative supply of oil, measured in units of butter; otherwise, the effect is reversed.

Next, we derive the equilibrium condition for the relative price of oil under autarky. Let $R^{i} \equiv R\left(p, \widetilde{T}^{i}-c_{r}^{G} G^{i}, L^{i}-c_{w}^{G} G^{i}\right)$ denote group $i$ 's revenue or GDP function contingent on the realization of the outcome of contest for land, $\widetilde{T}^{i}$. As before, this function is the maximized value of the group's gross domestic product or, equivalently, the minimized value of the group's expenditures on land and labor in the production of oil and butter:

$$
R^{i}=p X_{O}^{i}+X_{B}^{i}=r\left[\widetilde{T}^{i}-c_{r}^{G} G^{i}\right]+w\left[L^{i}-c_{w}^{G} G^{i}\right] .
$$

It is well-known that $X_{O}^{i}=R_{p}^{i}, w=R_{L}^{i}$, and $r=R_{T}^{i}$, where the subscripts on $R$ denote partial derivatives with respect to that variable [Dixit and Norman (1980)]. ${ }^{41}$

Maintaining the linear homogeneous specification for the representative consumer's preferences, group $i$ 's indirect utility function can be written as $V^{i}=\mu(p) R^{i}$ where as previously defined $\mu(p)$ is the marginal utility of income, with $\mu^{\prime}<0$ and $\mu^{\prime \prime}>0$. From Roy's identity, group $i$ 's contingent demand function for oil is $D_{O}^{i}=\alpha(p) R^{i} / p$, where $\alpha(p) \equiv-p \mu^{\prime}(p) / \mu(p)>0$ is the expenditure share on oil. ${ }^{42}$ It follows that group $i$ 's excess demand function for oil is $M^{i} \equiv D_{O}^{i}-X_{O}^{i}=\alpha(p) R^{i} / p-R_{p}^{i}$.

When there are no barriers to trade, the international price $p$ is taken as given. The country as a whole can be either a net importer $\sum_{i=1}^{N} M^{i} \equiv$ $\bar{M}(\bar{G}, p)>0$ or a net exporter $\bar{M}(\bar{G}, p)<0$. Under autarky, however, the

\footnotetext{
${ }^{41}$ Sharply pronounced asymmetries in the groups' contingent endowments can induce complete specialization in the production of oil or butter by some groups. Allowing for such specialization would require significant changes in the analysis. But, to keep focused on the issues at hand, we consider only the case of diversified production.

${ }^{42}$ With linear homogeneous preferences, denoted by $U^{i}$, group $i$ 's expenditure function is given by the following: $E^{i}\left(p, U^{i}\right)=e(p) U^{i}$, with $e^{\prime}(p)>0$ and $e^{\prime \prime}(p)<0$, where primes denote derivatives. One can easily verify that $(1) \mu(p) \equiv 1 / e(p) ;(2) \alpha(p) \equiv$ $-p \mu^{\prime}(p) / \mu(p)=p e^{\prime} / e(p)>0 ;(3) p \alpha^{\prime}(p) / \alpha(p)+\alpha(p)-1=p e^{\prime \prime}(p) / e^{\prime}(p)<0$.
} 
country can be neither. But since domestic markets are fully integrated, the autarkic price, $p_{A}$, is the price, given the allocation of guns by all groups, that satisfies the condition, $\bar{M}(\bar{G}, p)=0$. This condition implicitly defines the equilibrium price of oil, $p=p_{A}$, in units of butter, as a function of the country's aggregate endowments, given the aggregate allocation to guns, $\bar{G}$.

To derive that condition, define the country's aggregate revenue (or GDP) function as $\bar{R}=R\left(p, \bar{T}-c_{r}^{G} \bar{G}, \bar{L}-c_{w}^{G} \bar{G}\right)$. One can verify that $\bar{R} \equiv \sum_{i=1}^{N} R^{i}$ and further that $\bar{R}_{p}=\sum_{i=1}^{N} R_{p}^{i}\left(=\bar{X}_{O}\right)$. The condition for the autarkic price is then

$$
\bar{M}(\bar{G}, p)=\frac{\alpha(p)}{p} \bar{R}-\bar{R}_{p}=\frac{\bar{R}}{p}\left[\alpha(p)-\frac{p \bar{R}_{p}}{\bar{R}}\right]=0 .
$$

Note that $\frac{p \bar{R}_{p}}{R}=\frac{\rho}{1+\rho}$, the fraction of the country's GDP that comes from oil production. This fraction can be written as a function of the country's relative supply of oil. By applying the implicit function theorem (B.14), we will be able to identify the effect of a change in $\bar{G}$ on the autarkic price, $p_{A}$ :

$$
\frac{\partial p_{A}}{\partial \bar{G}}=-\frac{\bar{M}_{\bar{G}}}{\bar{M}_{p}}
$$

Tedious algebra shows that, $\bar{M}_{p}<0$, the condition for Walrasian stability, is satisfied. ${ }^{43}$ Hence, the sign of (B.15) is given by that of $\bar{M}_{\bar{G}}$.

From (B.14), market clearing requires $\alpha(p)-p \bar{R}_{p} / \bar{R}=0$. Using that

${ }^{43}$ Using (B.14), calculate:

$$
\begin{aligned}
\bar{M}_{p}= & \alpha^{\prime} \frac{\bar{R}}{p}-\alpha \frac{\bar{R}}{p^{2}}+\alpha \frac{\bar{R}_{p}}{p}-\bar{R}_{p p}-\bar{R}_{p T}\left(c_{r w}^{G} w_{p}+c_{r r}^{G} r_{p}\right) \\
& -\bar{R}_{p L}\left(c_{w w}^{G} w_{p}+c_{w r}^{G} r_{p}\right) .
\end{aligned}
$$

Since $\bar{R} / p \neq 0$, market-clearing requires $\bar{R}_{p}=\alpha \bar{R} / p$. Algebraic manipulations and substitutions, with that requirement, show that the first three terms can be written as $\alpha \bar{R}\left[p \alpha^{\prime} / \alpha-1+\alpha\right] / p^{2}$, which is negative since $\alpha$, the expenditure share for oil, is less than 1 and decreasing in $p$ [also see footnote 42]. Furthermore, the country's supply of oil is increasing in its price, $\bar{R}_{p p}>0$. Next, the linear homogeneity of the cost function for guns implies $c_{w r}^{G}=c_{r w}^{G}=-c_{w w}^{G} w / r=-c_{r r}^{G} r / w$. As such, one can simplify the last two terms of the expression as $-w r c_{w r}^{G}\left(r_{p} / r-w_{p} / w\right)^{2}<0$. Since $c_{w r}^{G}>0$ and $r_{p}>0$, while $w_{p}<0$, this simplified term is similarly negative. Thus, $\bar{M}_{p}<0$. 
requirement with the observation that $p \bar{R}_{p} / \bar{R}=\rho /(1+\rho)$, one can verify

$$
\bar{M}_{\bar{G}}=-\frac{\bar{R}}{p(1+\rho)^{2}} \frac{\partial \rho(\bar{G}, p)}{\partial \bar{G}} .
$$

Accordingly, by our assumption that $l_{B}>l_{O}$, we can use (B.12) to find

$$
\frac{\partial p_{A}}{\partial \bar{G}} \lesseqgtr 0 \text { if } l \lesseqgtr l_{G} .
$$

Thus, consistent with our finding in the main text, provided that butter is labor intensive $l_{B}>l_{O}$ and the labor-land factor intensity ratio in the production of guns exceeds the labor-land factor endowment ratio $l_{G}>l$, an exogenous increase in $\bar{G}$ implies an increase in $p_{A}$. It should also be clear by now that, as before, the autarkic price is independent of the outcome of the conflict. That is, $p_{A}$ is not subject to uncertainty.

\section{B.2.2 The effect of conflict on the pattern of trade}

To this point we have derived the equilibrium relationship between the relative price under autarky and the aggregate quantity of guns. Nothing has been said, however, about the optimizing choice of guns under either trade regime.

To proceed, we can define group i's expected payoff, as $W^{i}=\mu(p) \widehat{R}^{i}$, where $\widehat{R}^{i}$ is given by (B.13) with $\widetilde{T}^{i}$ replaced by $T^{i}+q^{i} T_{0}$. Focusing on identical groups, it is straightforward to show that the optimizing choice of guns by group $i$ (either under autarky or free trade) requires

$$
W_{G^{i}}^{i} \equiv \frac{W^{i}(G, p)}{\partial G^{i}}=\mu(p)\left[r T_{0} q_{G^{i}}^{i}-c^{G}\right]=0,
$$

where $r$ depends on $p$ as shown in (B.9). Aggregating this condition across all groups $i$, using $q_{G^{i}}^{i}=\left(\bar{G}-G^{i}\right) / \bar{G}^{2}$, yields the following:

$$
\sum_{i=1}^{N} W_{G^{i}}^{i}=\mu(p)\left[(N-1) T_{0} r / \bar{G}-N c^{G}\right]=0
$$


It follows that $\bar{G}^{*}=T_{0} \frac{N-1}{N}\left(c^{G} / r\right)^{-1}$. Since $c^{G}$ depends on factors prices, which in turn depend on price $p$, this solution and the Stolper-Samuelson theorem can be used to obtain

$$
\begin{aligned}
\frac{\partial \bar{G}^{*}}{\partial p} & =-T_{0} \frac{N-1}{N}\left(c^{G} / r\right)^{-2} \frac{\partial\left(c^{G} / r\right)}{\partial p} \\
& =T_{0} \frac{N-1}{N}\left(c^{G} / r\right)^{-2}\left(\frac{p w c_{w}^{G}}{r}\right)\left(\frac{p r_{p}}{r}-\frac{p w_{p}}{w}\right)>0 .
\end{aligned}
$$

The inequality follows from our assumption that $l_{B}>l_{O}$, as it implies that $p r_{p} / r>1$ and $w_{p}<0$. Now note that (B.17) together with (B.14) determine $p_{A}^{*}$ and $\bar{G}_{A}^{*}>0$. (B.17) alone determines $\bar{G}_{T}^{*}>0$. It should now be fairly clear how trade patterns where conflict is present compare with trade patterns in our hypothetical case of peace.

(i) Suppose that $l<l_{G}$ for all $\bar{G} \in\left[0, \bar{G}_{A}^{*}\right]$, so that $p_{A}^{*}<p_{A}^{n}$. Then, for any world price $p \in\left(p_{A}^{*}, p_{A}^{n}\right)$ the country will import oil under "Nirvana" and export oil under conflict if it could trade freely in the world market.

(ii) Suppose that $l>l_{G}$ for all $\bar{G} \in\left[0, \bar{G}_{A}^{*}\right]$, so that $p_{A}^{*}>p_{A}^{n}$. Then, for any world price $p \in\left(p_{A}^{n}, p_{A}^{*}\right)$, the country will export oil under "Nirvana" but import oil under free trade with conflict. 